\title{
Effectiveness of policy and regulation in European sovereign credit risk markets - A network analysis
}

by Rebekka Buse, Melanie Schienle and Jörg Urban

No. 125 | JANUARY 2019

\section{WORKING PAPER SERIES IN ECONOMICS}

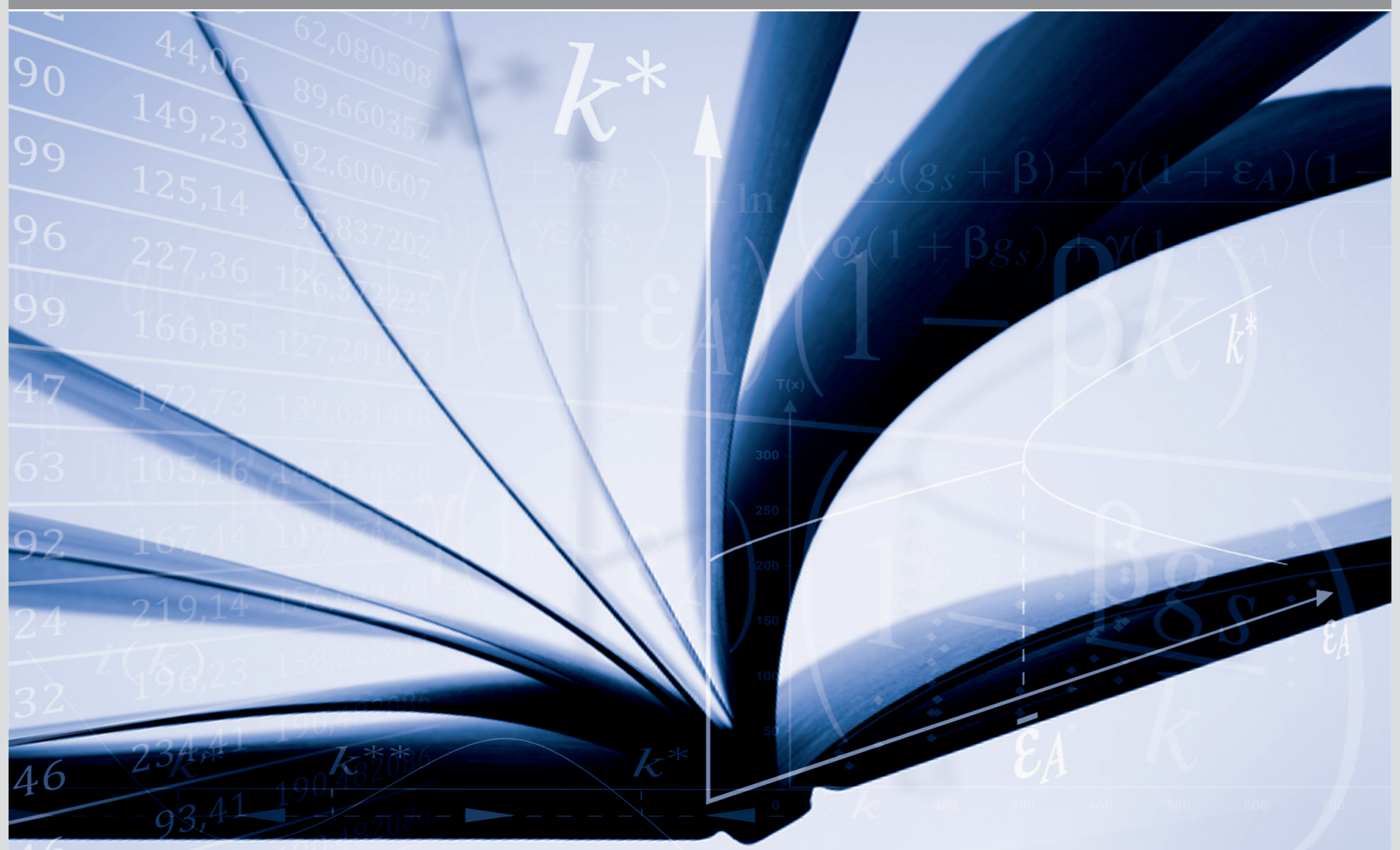




\section{Impressum}

Karlsruher Institut für Technologie (KIT)

Fakultät für Wirtschaftswissenschaften

Institut für Volkswirtschaftslehre (ECON)

Kaiserstraße 12

76131 Karlsruhe

KIT - Die Forschungsuniversität in der Helmholtz-Gemeinschaft

Working Paper Series in Economics

No. 125, January 2019

ISSN 2190-9806

econpapers.wiwi.kit.edu 


\title{
Effectiveness of Policy and Regulation in European Sovereign Credit Risk Markets - A Network Analysis|*
}

\author{
Rebekka Buse
}

\author{
Melanie Schienle
}

January 8, 2019

\begin{abstract}
We study the impact of changes in regulations and policy interventions on systemic risk among European sovereigns measured as volatility spillovers in respective credit risk markets. Our unique intraday CDS dataset allows for precise measurement of the effectiveness of these events in a network setting. In particular, it allows discerning interventions which entail significant changes in network cross-effects with appropriate bootstrap confidence intervals. We show that it was mainly regulatory changes with the ban of trading naked sovereign CDS in 2012 as well as the new ISDA regulations in 2014 which were most effective in reducing systemic risk. In comparison, we find that the effect of policy interventions was minor and generally not sustainable. In particular, they only had a significant impact when implemented for the first time and when targeting more than one country. For the volatility spillover channels, we generally find balanced networks with no fragmentation over time.
\end{abstract}

JEL codes: G20, G01, G17, C32, C55, G28

Keywords: Financial Crises, Policy and Regulation, Financial Stability and Systemic Risk in the Eurozone, High-frequency CDS, bootstrap spillover-measures

* The authors thank Kristyna Ters, seminar participants at the European systemic Risk Boards, the Bank for International Settlements (BIS), the HeiKaMEtrics Conference, the HeiKaMEtrics Workshop and ScienceFore. Jörg Urban contributed to this paper while at the BIS. The views expressed in this work do not necessarily reflect those of the BIS. This research has been supported by WWZ Forum under project FV-59 and by DFG under grant SCHI-1172.

$\dagger$ Karlsruher Institut für Technologie, Karlsruhe, Germany. Email: rebekka.buse@kit.edu

¥ Karlsruher Institut für Technologie, Karlsruhe, Germany. Email: melanie.schienle@kit.edu

$\S$ University of Basel, Basel, Switzerland. Email: joerg.urban@unibas.ch 


\section{Introduction}

There is large empirical evidence that markets have calmed down after the recent EU sovereign crisis. But it remains still unclear if and to what extend it is policy interventions or rather regulatory changes which have impacted and mitigated systemic risk most significantly. Though a thorough understanding is crucial for judging the current and long run implications for the resilience of the system. We use novel intraday sovereign CDS and bond data for the years 2009-2014 which comprises both, policy interventions and regulatory actions such as the SMP programs, the ban of trading naked sovereign CDS or the new ISDA rules. We show that with the higher than daily observation frequency it is possible to empirically disentangle, record the impact and judge the significance of the different types of events. This complements the many studies on the evolution of systemic risk in the EU sovereign context in the course of policy interventions, which rely only on shorter span daily data before and just shortly after the most important regulatory measures were implemented $\mathbb{1}$. Thus the limitation of the data prevented investigations on the impact of regulatory changes, and even derived point estimates for policy interventions before remained of unknown precision. In contrast, we provide finite sample adequate bootstrap tools to assess if changes in systemic risk are significant. In order to obtain tight confidence intervals for the impact of tightly succeeding events, high-frequency observations are key. In this sense, we contribute to the vast literature on providing point estimates of systemic risk measured as spillover effects in a network set-up (see e.g. Diebold and Yilmaz (2014), Hautsch et al. (2015), Engle et al. (2014), Betz et al. (2016)).

For assessing systemic risk we focus on volatility spillovers. Technically, we determine interconnections via the order invariant generalized forecast error variance decomposition (see Pesaran and Shin (1998)). We go beyond the status quo of only computing point estimates of unknown precision for this measure (see e.g. Diebold and Yilmaz (2014)) and assess the statistical significance of connectedness by constructing bootstrap confidence intervals. Thus, we can distinguish significant volatility effects from others and thus infer which changes in the measures allow for a meaningful interpretation. In particular, we can apply this to all aggregation levels of the detected spillover network. We can therefore discover significant overall aggregated spillover changes over time but also determine significant spillover channels on the network level at each point in time. This approach enables us to comprehensively evaluate and categorize the effectiveness of crisis-related policy measures and regulation in the CDS

\footnotetext{
1 Most of the empirical studies in fact only use daily data until 2012/13 (see e.g. Diebold and Yilmaz (2014), Alter and Beyer (2014)) where the short-selling ban for sovereign CDS was just introduced and the new ISDA rules have not been implemented and/or focus only on ECB policy interventions (see Eser and Schwaab (2016), Falagiarda and Reitz (2015) or Gibson et al. (2016) and Arghyrou and Kontonikas (2012)).
} 
market. It is important to note that all our empirical results do not depend on the fact that we use variance decomposition for measuring volatility spillovers or a specific type of decomposition method (see A.Chan-Lau (2017)). In particular, we show in detail that our results prevail when using realized volatility cross-effects.

Our novel intraday CDS dataset allows for a better accuracy in estimating spillovers and judging the impact of policy and regulation measures on the dynamics of the European sovereign CDS market. Up to our knowledge, this is the first study investigating the significance of connectedness using intraday CDS data. In particular due to this intraday data, it is possible to evaluate the connectedness on a high precision level. This is especially important when studying the impact of specific events on reducing systemic risk where spillovers in respective pre- and post-event windows are compared in order to judge the effectiveness of this policy or regulatory event (see also Ghysels et al. 2014). For our intraday data, there are sufficiently many observations within estimation windows of only a few trading days in order to obtain meaningfully precise estimates. Larger windows covering more trading days would inevitably contain effects of other closely succeeding events and dilute the picture.

We investigate the two most important regulatory changes in the EU sovereign CDS market and show evidence for their success in terms of reducing connectedness and speculation in affected countries. First, we study the permanent ban of so-called 'naked sovereign CDS' contracts implemented in 2012. Second, we focus on the introduction of new CDS definitions and standard reference obligations in 2014 which marked an important change to CDS trading. By quantifying volatility spillovers on all network aggregation levels and taking liquidity effects into account, we uncover the size, the channels and the drivers of the impact of the ban and the new definitions. In particular, we show that there is more than a simple liquidity story behind the success of the ban and the new ISDA regulation. Moreover, throughout the crisis, we cannot determine any fragmentation within our CDS sovereign spillover networks and thus conclude that there must be multiple sources of contagion. This insight goes beyond previous studies (see e.g. Ehrmann and Fratzscher (2017)) with bond yields which in contrast to CDS, have been shown to suffer from many problems in representing credit risk (see Pan and Singleton (2008) and Ang and Longstaff (2011)). In addition, we provide evidence for public learning effects in unconventional monetary policy measures leading to a decrease of their effectiveness. Furthermore, European-wide measures prove to impact connectedness in a more sustainable manner than measures aimed at one particular country. Unconventional policy interventions which aimed at mitigating systemic risk include economic adjustment programs (EAP) (two for Greece, one for Ireland, Portugal and Spain) and the bond purchases as part of the Security Markets Program (SMP) of the ECB, which was succeeded by the OMT program. The OMT was introduced after Draghi's speech stating the ECB would do 'whatever it takes' to 
sustain the Euro. Both the SMP and Draghi's speech are examples of European-wide interventions.

Forecast error variance decomposition was applied in several studies of the euro area sovereign debt crisis to understand interactions of markets, institutions and sovereign entities. Alter and Beyer (2014) extend the framework of Diebold and Yilmaz (2014) to measure spillovers between sovereign entities and banks in the euro area using daily data. They find, that the EAPs had a mitigating effect on systemic risk for Greece, Ireland and Portugal. Compared to their results we achieve a higher estimation precision thanks to the use of intraday data, and therefore can judge the effectiveness of policy interventions more precisely by using shorter estimation windows. Furthermore, our data allows to compute bootstrapped confidence intervals and hence statistically validated our results. Claeys and Vašíček (2012) and Claeys and Vašíček (2014) employ a factor augmented Diebold-Yilmaz approach to estimate bilateral spillovers between 16 EU sovereign entities. Unlike them, we focus on the core countries affected by the crisis, namely Greece, Ireland, Italy, Portugal and Spain, as well as France and Germany as control/risk-free countries. These countries have also the most liquid CDS and bond markets. Focusing on the most relevant countries improves the statistics because less parameters need to be estimated to perform an error variance decomposition. Nevertheless, we test our results by including four additional euro area sovereign entities $2^{2}$ and find robust outcomes. Claeys and Vašíček (2012) and Claeys and Vašíček (2014) find similar to our findings substantial spillovers (connections), however they report that contagion is a rare phenomenon, also in line to our finding that there is no segregation in the networks. The usage of daily bond data forces Claeys and Vašíček (2012) and Claeys and Vašíček (2014) to use also very long estimation windows. The use of intraday data and the computation of confidence intervals by using a bootstrap methodology hugely increases the computational burden, but both novelties are in our view mandatory. First the judgment of the impact of policies and regulations is only possible by knowing their statistical significance. Second, credit risk instruments are fast reacting to news, hence an intraday frequency is necessary. Although we are the first to use intraday CDS data to study connectedness, the advantages of intraday data in general has been pointed out by several papers. Neil and Fillion (1999) have already stressed that high frequency data should be used to assess the impact of interventions. Similarly, Ghysels et al. (2014) argue that daily data is not sufficient to assess the effectiveness of the SMP. For further discussions see Ters and Urban (2016), Gyntelberg et al. (2017) and Gyntelberg et al. (2018).

A key advantage and novelty of our analysis compared to the above mentioned papers is that we extend the period to capture the calming down of the euro area sovereign debt crisis and to include the new ISDA regulation in 2014 into our analysis.

$\overline{2}$ We add as a robustness check Austria, Belgium, Finland and The Netherlands. 
Compared to the ISDA regulation, the academic discourse on the ban on short-selling of naked sovereign CDS has a long history and has split academics and practitioners into two camps. One part is claiming that the ban has been counter-productive, leading to a drastic liquidity reduction and one part praises the success of the ban. Our results support the latter, i.e. they are in line with Kiesel et al. (2015) who also show that banning naked sovereign CDS has stabilized markets and reduced speculation. Portes (2010) was one of the first academics calling for the implementation of a ban. Oehmke and Zawadowski (2015) on the other hand provide a model of CDS which shows, that a ban on naked CDSs can raise borrowing costs. However, their model predicts a negative CDS-bond basis, which we can empirically not verify for sovereign CDS. We show that the observed CDS-bond basis is almost always positive. Short-selling bans have also been analyzed for other markets, e.g. Beber and Pagano (2013) examined stock markets and found reduced liquidity and a slow-down of the price discovery process. However, a direct comparison with our findings is difficult, because bans on stocks were only temporary and limited to certain stocks.

Research on the effectiveness of the ECB's unconventional policy measures mainly focused on the ECB's asset purchasing programs and analyzed bond yield data, see for example Eser and Schwaab (2016), Falagiarda and Reitz (2015) or Gibson et al. (2016). Arghyrou and Kontonikas (2012) analyse the euro area debt crisis using daily bond data focusing on contagion amongst sovereign entities. Our paper opens up a new dimension by analyzing the effects of policies on CDS markets of both asset purchasing programs as well as EAPs. We prefer CDS data as a measure of sovereign default risk to bond yield spreads or asset swap spreads because CDS spreads are less affected by funding liquidity and flight-to-safety issues (see Pan and Singleton (2008) and Ang and Longstaff (2011)). According to our knowledge we are the first to consistently analyze ECB programs, economic adjustment programs, the ban of naked sovereign CDS as well as the ISDA regulations from 2014.

The paper is organized as follows: The following Section 2 carefully describes the intraday data. The model and methods are explained in Section 3 . Section 4 details the results. Section 5 concludes the paper.

\section{Data}

Our intraday CDS data consists of price quotes provided by CMA (Credit Market Analysis Ltd.) Datavision. CDS are traded over-the-counter (OTC), which makes the data collection and checking challenging. CMA continuously gathers information on executable and indicative CDS prices directly from the largest and most active credit investors. After cleaning and checking the individual quotes, CMA applies a time and liquidity weighted aggregation so that each reported bid and offer price is 
based on the most recent and liquid quotes. A detailed descriptive statistics of our data are presented in Appendix A.1. The dataset has specific characteristics which require a closer investigation. The two most important aspects are the number of observations and the intra-daily volatility. First, as can be seen from the average number of observations per day in Table 2, there are less observations in 2009 and from mid 2014 onwards. Second, the data provider changes the data aggregation model from 2013 onwards, leading to higher volatility of the data. We show in Appendix A.2 that both of these specifics do not affect our results. The time series of CDS spreads are presented in Figure 1. The evolution of euro area sovereign CDS spreads clearly shows the severity of the euro area sovereign debt crisis, as compared to the financial crisis with only a small peak after the Lehman default in 2008. Figure 1 also indicates that the time from 2009 until end of 2014 is indeed the most relevant period.

Most of the activity for European sovereign entities in the CMA database is concentrated between 8:30 and 17:30? which is why we restrict our intraday analysis to this period. The available number of indicative tick-by-tick quotes for CDS does not allow higher equidistant data frequency than 30 minutes. Hence, we have 18 data points or time-stamps per day. We have tested, that for the 30 minute-aggregation of intraday data, we do not observe microstructure noise or volatility smiles which are typical for high-frequency data. The euro area sovereign CDS markets were thin prior to 2009, which makes any type of intraday analysis before 2009 challenging. Therefore, we analyze the CDS market from 2009 until 2014 and focus on 5 year USD denominated CDS which are most liquid ${ }^{4}$

We use CDS spreads of seven countries: Greece (GR), Ireland (IE), Italy (IT), Portugal (PT) and Spain (ES), the countries which were most affected by the European sovereign debt crisis, as well as France (FR) and Germany (DE) 5 Germany is included as a risk-free country and France as a near risk-free control country. Reliable data for Greece is only available until June 2011. CDS trading for Greece ceased entirely with the restructuring in early 2012.

Most missing values are due to bank holidays. The following treatment of missing values is carried out for a total of 27,180 time stamps between 2009 and 2014, which amounts to approximately 163,080 observations 6 : If, at a given time stamp, four countries or more have missing values, the entire time stamp is removed which amounts to $7.6 \%$ of all time stamps. The rational behind this procedure is our aim to analyze all

3 All times quoted refer to Central European Time (CET).

4 Sovereign CDS contracts are typically denominated in a currency different from the main tender of the deliverable obligations. The main reason for this is that faced with a credit event, it is assumed that the local currency will come under considerable pressure.

5 We verify that our results are not affected by the choice or number of selected countries by repeating the analysis with four additional euro area members: Austria, Belgium, Finland and the Netherlands. The results are almost identical and are provided in Appendix A.3

6 These figures concern the entire dataset from 2009 until 2014 without Greek data. 
countries together in a network analysis. After removing these timestamps, the dataset contains 25,107 timestamps and a total of 150,642 observations. The remaining 2,434 missing observations in the CDS dataset are interpolated via Kalman smoothing.7

Since liquidity plays an important role especially for the analysis of CDS market regulations, we consider various liquidity proxies, all of which are plotted in Appendix A.4. First, we compute intraday relative bid-ask spreads 8 from the data provided by CMA. In addition, we examine weekly CDS-trading volume from the Depository Trust and Clearing Corporation (DTCC) in form of net notional outstanding and trade counts.

Figure 1: CDS levels

The figure illustrates the time evolution of CDS spreads based on intraday data. The data is plotted from 2008 onwards to show the impact of the collapse of Lehman Brothers compared to the sovereign debt crisis.
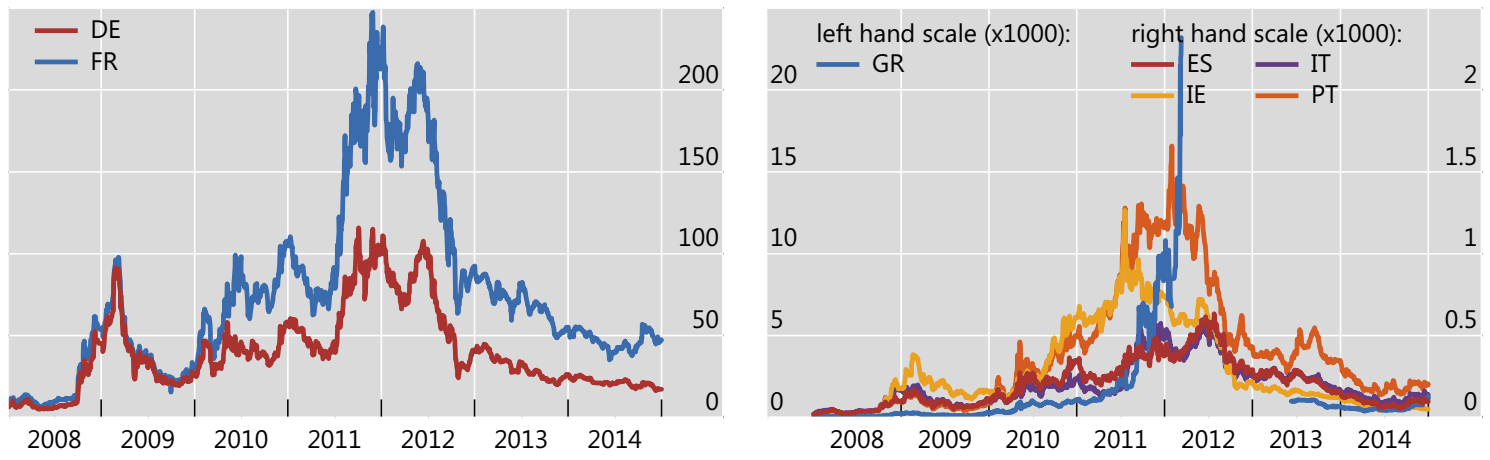

We test for unit roots and stationarity using the Augmented Dickey-Fuller (ADF) test, the Phillips-Perron (PP) test and the Kwiatkowski-Phillips-Schmidt-Shin (KPSS) test (see Appendix A.1). All tests consistently indicate that the system of EU sovereign CDS returns is nonstationary of unit root type, hence in our analysis we use first differenced data, i.e. returns.

\section{Model}

\subsection{Dynamic volatility spillover networks}

We identify interconnection channels in the EU sovereign credit risk market from timevarying volatility spillover networks of the respective sovereign CDS market. Such dynamic networks are essentially characterized by an adjacency matrix $S=\left(\left(s_{i j}\right)\right)_{i j}$

\footnotetext{
7 We have also implemented linear interpolation as a robustness check and find that the two interpolation methods lead to equivalent results.

8 Relative bid-ask spreads are defined as (ask price-bid price)/((ask price+bid price)/2).
} 
containing all volatility cross-effects in the system at each point in time. If we have adequate econometric techniques to obtain estimates of $S$ over time (see below) then with each element $s_{i j}$ we can characterize the size of the impact from country $j$ to $i$ at each point in time. In particular, we obtain the directed relative effect as

$$
\widetilde{s}_{i j}=\frac{s_{i j}}{\sum_{l=1}^{K} s_{i l}}
$$

where $K$ represents the number of countries in the network (in our case $K=7$ ) and the time index is suppressed for notational convenience. We call $\widetilde{s}_{i j}$ the individual connectedness in accordance with the literature (Diebold and Yilmaz $(\overline{2009})$ ). Note that the row normalization in Equation (1) causes impacts to be directed apart from generating row-wise and thus country-wise comparable percentage values. The resulting connectedness matrices $\widetilde{S}=\left(\left(\widetilde{s}_{i j}\right)\right)_{i j}$ are interpreted as directed adjacency matrices and their components $\widetilde{s}_{i j}$ mark the strength of the effect in the directed edge of node $j$ on $i$ in a network graph. Moreover, we also work with the following two aggregate characteristics of the network, summarizing country-wise and overall effects, respectively. In particular, all connectedness that entity $j$ transfers to all other entities of the system is denoted as country-wise connectedness and computed as a weighted out-degree network descriptive statistic for country $j$ :

$$
\widetilde{s}_{j}=\sum_{i=1, i \neq j}^{K} \widetilde{s}_{i j} .
$$

The network density of the entire system aggregates all cross-correlation spillover effects by summing up all off-diagonal elements of $\widetilde{S}$ :

$$
\widetilde{s}=\frac{1}{K} \sum_{i, j=1, i \neq j}^{K} \widetilde{s}_{i j} .
$$

It is denoted by total connectedness. Note that the normalisation $1 / K$ in Equation (3) ensures that the total connectedness and the country-wise connectedness are on the same scale (see Diebold and Yilmaz (2014)).

If we stack all $K=7$ considered EU sovereign CDS returns in a system vector $\mathbf{y}_{\mathbf{t}}$, there are several options to obtain the volatility based directed network adjacency matrix $\tilde{S}$ over time. The most straightforward and simple way, is to calculate simple descriptive realized correlations

$$
s_{i j}^{d}:=\operatorname{RCorr}_{i j}=\frac{\sum_{t=1}^{T^{\prime}} y_{t i} y_{t j}}{\sqrt{\sum_{t=1}^{T^{\prime}} y_{t i}^{2} \sum_{t=1}^{T^{\prime}} y_{t j}^{2}}}
$$


in rolling windows of length $T^{\prime}$ over time $t=1, \ldots, T$.

In this paper, however, we take a different route with an underlying dynamic system model which thus allows for forecasting and inference in the spillover measures. With this, it is also possible to characterize the surprise effect of events which makes it especially suitable for evaluating crisis periods and unconventional policy or regulation interventions (Buse and Schienle $(2019))$. In our setting, the adjacency matrix $S=\left(\left(s_{i j}\right)\right)_{i j}$ is derived from the forecast error variance of an appropriate vector autoregression (VAR) model for a subperiod 9 . In particular, we use variance decomposition (Lütkepohl, 2006) to determine the effect of a shock in entity $j$ on the forecast error variance in entity $i$ as $s_{i j}$. This corresponds to the approach in Diebold and Yilmaz (2014).

In order to estimate the variance decomposition components, we first model $\mathbf{y}_{t}$ as a VAR for any sub-period of length $T_{e}$ as

$$
\mathbf{y}_{t}=\sum_{i=1}^{p} A_{i} \mathbf{y}_{t-i}+\mathbf{u}_{t}, \quad t=1,2, \ldots, T_{e},
$$

where $A_{i}$ are the $(K \times K)$ coefficient matrices and $\mathbf{u}_{t}$ is a white noise process with zero mean $\left(E\left(\mathbf{u}_{t}\right)=\mathbf{0}\right)$ and variance $E\left(\mathbf{u}_{t} \mathbf{u}_{t}^{\prime}\right)=\Sigma_{u}$ with elements $\sigma_{i j}$ and $E\left(\mathbf{u}_{t} \mathbf{u}_{s}^{\prime}\right)=0$ for $t \neq s$. Note that we have ensured that $\mathbf{y}_{t}$ is covariance-stationary thus there exists a moving average representation $\mathbf{y}_{t}=\sum_{i=0}^{\infty} \Phi_{i} \mathbf{u}_{t-i}$. As our main goal is the analysis of relevant effects of novel policy and regulation measures the underlying dynamic structure of the system cannot be captured in a static VAR over the entire sample length $T$. Instead we require substantial model flexibility allowing for different VAR specifications in different subperiods. Please see the subsequent Subsection 3.2 how we determine the length of $T_{e}$ and the respective $p$ in Equation (5) empirically. Moreover for our event study, the rolling window based approach is superior in econometric accuracy to a general time-varying parameter VAR model for the full sample which can only capture smooth changes over time. Please also see the next subsection how we empirically ensure that estimation sub-intervals are small enough that there are no jumps in parameter values in the VAR in Equation (5).

Then the $H$ step ahead forecast error variance of the system can be derived using a moving average (MA) representation of (5) for any sub-period.

$$
E\left[\left(\mathbf{y}_{t+H}-\mathbf{y}_{t}(H)\right)\left(\mathbf{y}_{t+H}-\mathbf{y}_{t}(H)\right)^{\prime}\right]=\sum_{h=0}^{H-1}\left(\Phi_{h} \Sigma_{u} \Phi_{h}^{\prime}\right),
$$

9 VAR models have been widely used in the literature to assess contagion (see for example Ahelegbey et al. 2016) 
where $\Phi_{h}$ is the $h$-th coefficient of the MA-representation. $\mathbf{y}_{t}(H)$ represents the theoretical optimal predictor and can be written in MA-representation as $\mathbf{y}_{t}(H)=\sum_{i=H}^{\infty} \Phi_{i} \mathbf{u}_{t+H-i}$, for known $\Phi_{i}$. In order to obtain a valid connectedness measure, we use variance decomposition of the forecast variance matrix in Equation (6). In particular, we employ the generalized variance decomposition (see Koop et al. (1996), Pesaran and Shin (1998)) which is generally preferred to Cholesky decomposition since it is independent of variable ordering. For each entity $i, j=1, \ldots, K$, the variance decomposition component for $H$ forecast steps ahead is given by

$$
s_{i j}(H)=\frac{\sigma_{j j}^{-1} \sum_{h=0}^{H-1}\left(e_{i}^{\prime} \Phi_{h} \Sigma_{u} e_{j}\right)^{2}}{\sum_{h=0}^{H-1}\left(e_{i}^{\prime} \Phi_{h} \Sigma_{u} \Phi_{h}^{\prime} e_{i}\right)} .
$$

where $e_{l}$ is a unit vector in $T_{e}$, which is 1 in its $l-t h$ component and zero otherwise. For a detailed derivation of Equation (7) please see Appendix A.5. For our empirical analysis, we set $H=1$, i.e., we generally compute variance decomposition matrices for one forecast step ahead. This is without loss of generality, since meaningful alternatives with $H=18$ (one day) and $H=90$ (one week) forecast steps ahead yield nearly identical results 10 For notational convenience, we write $s_{i j}$ instead of $s_{i j}(H)$ in the sequel.

\subsection{Empirical determination of network effects}

We empirically determine network spillovers in the EU sovereign credit risk market from the variance decomposition of the forecast error variance of an underlying VAR in the system. In particular, we focus on size and significance of the impact of the 9 key monetary policy actions and 5 most important regulatory changes on (aggregate) network cross-effects in the years 2009-2014 as displayed in Figure 2.

For the volatility spillover measures, we generally aim for a parsimonious model fit in the underlying VAR specification. In particular, the lag order $p$ of the VAR-model is selected according to the Akaike information criterion (AIC) ${ }^{11}$ for each estimation window and is restricted to a maximum lag order of three. Including a constant does not improve the model fit. For the analysis of connectedness across time we use a rolling window approach, which incorporates dynamic effects (see Figure 2). The window width only affects the variability but not the dynamic structure of the resulting connectedness, which we have compared for different window sizes between 5 days (90 observations) and 40 days (720 observations) with and without Beta-weighting scheme ${ }^{12}$, However, wider rolling windows incorporate effects of certain events for a

\footnotetext{
${ }^{10}$ Results are provided upon request.

11 Akaike performs better than Schwarz in small samples (Lütkepohl, 2006).

12 For more details on the beta-weighting scheme see Ghysels et al. (2007).
} 
Figure 2: Time line events and total connectedness

The figure illustrates total connectedness with 90\% confidence intervals. Crisis related events are marked as black lines and regulatory interventions are shown by purple lines. The connectedness is computed with a rolling window of 20 trading days and take daily steps for new windows. A fixed number of days implies that when observations are missing, there might be less than 360 observations in one estimation window.

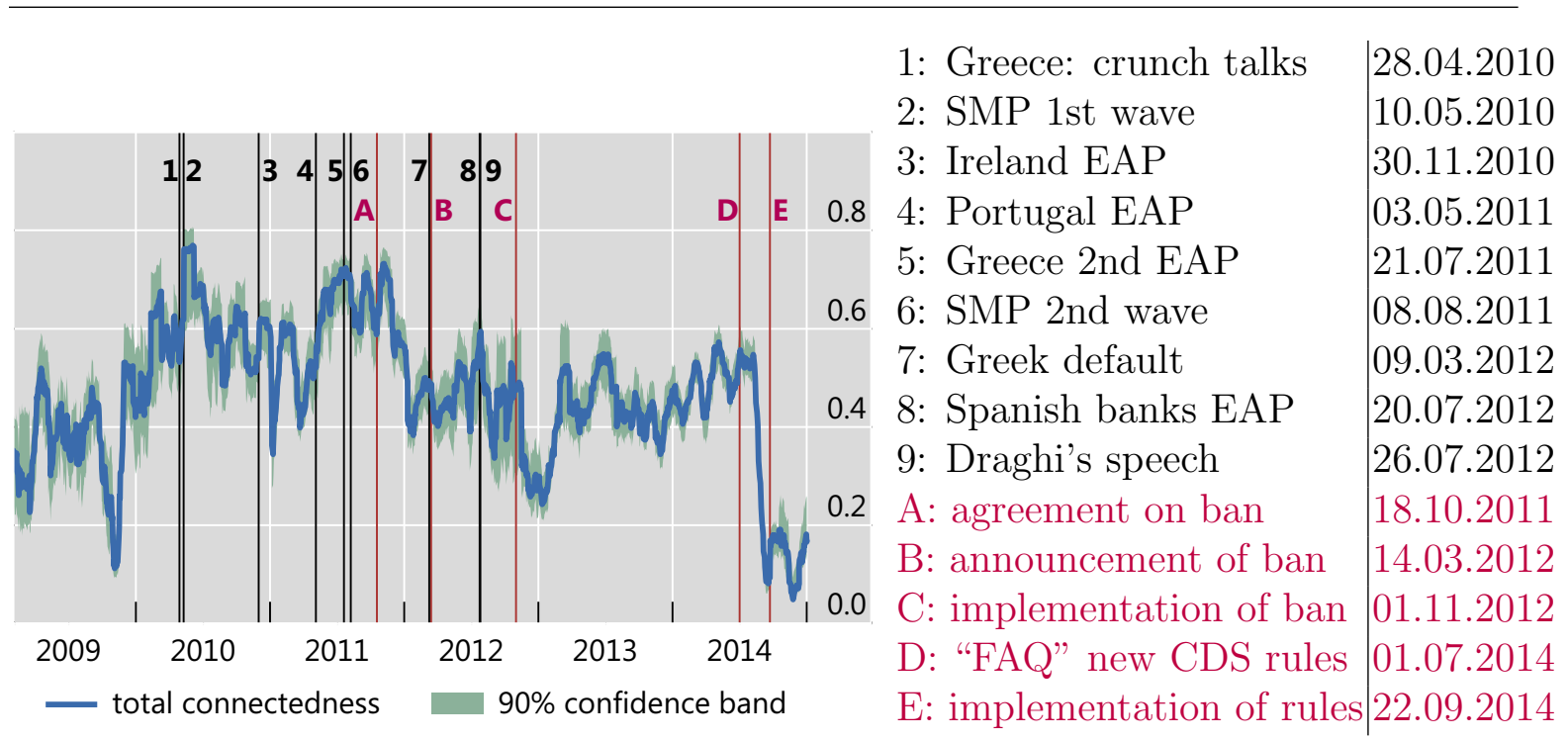

longer time period. We only want to focus on the effects of each individual event and not include a long history of data which may include other effects. Therefore, in order to discern effects on connectedness of events that lie close by one another, it is useful to work with shorter rolling windows. For regulatory changes characterized by a lengthy process we set the rolling window size to 180 observations and for the short-term analysis of crisis-related policy events we look on a finer scale of 90 observations for each window ${ }^{13}$. We also compare individual connectedness (see Equation (1)) based on preevent and post-event windows to evaluate the effectiveness of interventions. The preand post-event connectedness networks are calculated using data of five trading days prior to and after an event, whereby the post-event window is shifted by four trading days 14

\footnotetext{
${ }^{13}$ Due to missing data 90 (180) timestamps may correspond to slightly more than five (ten) trading days.

${ }^{14}$ The rational behind the shift of the start of the post-event window by four days is that we want to analyze the medium to long-term effectiveness of the interventions on the network (connectedness) and not the short-term joint adjustment of the CDS spreads of all entities due to the event. The joint short-term co-movement of markets results in a short-term strengthening of connectedness. The four days shift is chosen based on the assumption that credit risk markets react fast to news (see e.g. Daniels and Jensen, 2005). Gyntelberg et al. (2013) have found half-lives which were on average four days during the crisis period. We have repeated the computation with a shift of three and five days and observe robust results.
} 
The OLS-based MOSUM stability test (Chu et al., 1995; Kuan and Hornik, 1995) yields evidence of no structural breaks for rolling window sizes of 90 and 180 observations at a significance level of 10\%. This is in line with Blatt et al. (2015), who show that structural breaks are less important for small estimation windows. We also verify that heteroscedastic effects are negligible in our data set by applying an ARCH-LM-test as proposed by Engle (1982) and a multivariate Portemanteau test for serial correlation, adjusted for small sample sizes to each estimation window (of size 180). Since the most important part of the data is not significantly affected by heteroscedasticity 15 and in favor of a parsimonious model we exclude heteroscedastic effects from the model. Thus an underlying VAR dynamic specification in rolling windows (5) captures the system dynamics in an adequate way.

Our obtained network results are independent from our underlying dynamic model specification and variance decomposition method. We illustrate this by comparing the total connectedness derived from $s_{i j}$ of the variance decomposition in Equation (7) to the one based on $s_{i j}^{d}$ from Equation (4) using model-free realized correlation (see Figure 3). In Figure 3 we see that the dynamics of the two measure are very similar. Therefore, the dynamics of the resulting connectedness measures does not appear to be impacted by specification choices of the underlying model. Thus we conclude that our

Figure 3: Realized correlation versus variance decomposition

The figure shows the total connectedness based on correlation and on variance decomposition. The realized correlation is computed for rolling windows of $T^{\prime}=20$ trading days.

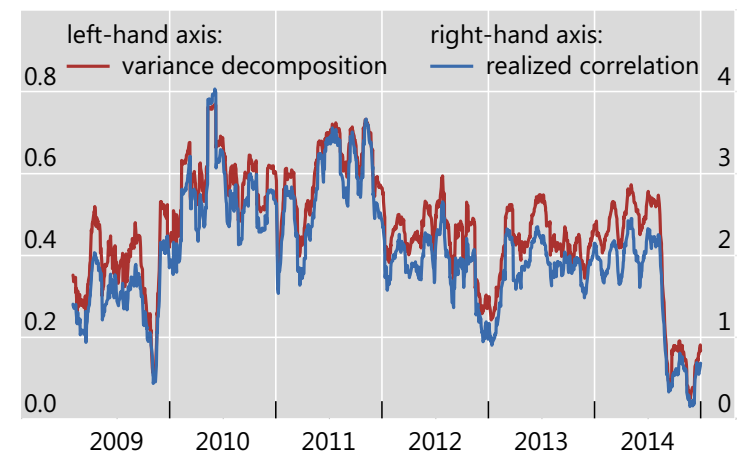

empirical results in the following are not specific to the variance-decomposition type of spillover measures we use but they prevail in general and thus constitute robust findings.

\footnotetext{
15 Results of both tests show that for the large part, the null of no heteroscedasticity cannot be rejected. The only exception to this is the period before October 2010 for ARCH-tests and the last part of the data after December 2013 for the Portemanteau test in which only few rolling windows show evidence for heteroscedasticity.
} 


\subsection{Significance and precision of volatility impact measures}

One main technical contribution of this paper is that, in addition to the point estimates of network spillover measures, we also evaluate the respective statistical accuracy of these measures. In particular, we provide bootstrap procedures for deriving the precision of these measures on all network aggregation levels which are valid even if the amount of available data in between successive events is scarce. Hence, we can determine statistically significant effects and distinguish them from less relevant spillovers which might be negligible when evaluating the impact of crisis events, or policy and regulation measures on connectedness.

Bootstrap confidence intervals are commonly computed for impulse response functions (Lütkepohl, 2000) using the MA-representation of the underlying VAR(p) dynamics in Equation (5). The following bootstrap method is applied for $B=1000$ repetitions:

1. Use OLS to derive estimates $\hat{A}$ of the $\operatorname{VAR}(\mathrm{p})$ parameters and $\hat{\Phi}_{i}$ of respective MA coefficients in Equation (5) and obtain corresponding centered residuals $\tilde{\mathbf{u}}_{t}=$ $\hat{\mathbf{u}}_{t}-\overline{\hat{\mathbf{u}}}_{t}, t=1, \ldots, T_{e}$.

2. Construct $b=1, \ldots, B$ series of bootstrap residuals $\left(\hat{\mathbf{u}}_{1}^{*, \mathbf{b}}, \ldots, \hat{\mathbf{u}}_{T_{e}}^{*, \mathbf{b}}\right)$ by resampling with replacement for $t=1, \ldots, T_{e}$ from the centered residuals $\tilde{\mathbf{u}}_{t}$, for $t=1, \ldots, T_{e}$.

3. Construct the bootstrapped time series recursively as $\mathbf{y}_{t}^{*, b}=\sum_{i=0}^{\infty} \hat{\Phi}_{i} \mathbf{u}_{t-i}^{*, b}$ for $b=1, \ldots, B$. Obtain bootstrapped estimates $\hat{A}^{*, b}$ and ${\hat{\Phi_{h}}}^{*, b}$ using OLS for $\mathbf{y}_{t}^{*, b}$ in Equation (5).

4. Use new bootstrap time series to compute $s_{i j}^{*, b}(H)=\frac{\left(\sigma_{j j}^{*, b}\right)^{-1} \sum_{h=0}^{H-1}\left(e_{i}^{\prime} \Phi_{h}^{*, b} \sum_{u}^{*, b} e_{j}\right)^{2}}{\sum_{h=0}^{H-1}\left(e_{i}^{\prime} \Phi_{h}^{*, b} \Sigma_{u}^{*, b} \Phi_{h}^{*, b^{\prime}} e_{i}\right)}$ as in Equation (7). This yields the connectedness measures $\tilde{s}_{i j}^{*, b}(H), \tilde{s}_{i}^{*, b}(H)$ and $\tilde{s}^{*, b}(H)$ analogous to Equations (1) to (3) for all $b=1, \ldots, B$.

5. Define network confidence interval $C I(1-\alpha)$ as $C I(1-\alpha)=\left[q_{\alpha / 2}, q_{1-\alpha / 2}\right]$ where $q_{\alpha / 2}$ and $q_{1-\alpha / 2}$ are the respective quantiles of the empirical distribution of $\tilde{s}^{*, b}(H)$ over all $b=1, \ldots, B$.

Note that we set precision bounds with respect to total connectedness. These constitute the statistically adequate finite sample confidence intervals for the overall network density over time and allow to judge overall significant effects of events on total connectedness in the system. Technically, it would also be possible to derive confidence intervals for country-wise or element-wise connectedness within each network at each point in time. But we decided to assess these more granular network measures all with respect to a single network-specific accuracy interval per point in time instead of individual quantities $\sqrt{16}$ Thus evaluation of relevant network spillovers occurs by a common shared benchmark and which is computationally attractive to obtain.

${ }^{16}$ Note that by construction, individual connectedness is not necessarily smaller (larger) for the lower (upper) confidence interval boundary from total conncetedness. 


\section{Results}

During the European sovereign debt crisis there have been various efforts to stabilize and calm markets. We investigate how these interventions affected connectedness respective systemic risk in credit-risk markets using intraday CDS spreads. In addition, we analyze the channels of the volatility spillovers and investigate the topology of corresponding cross-effect networks. The considered period from 2009 until the end 2014 contains crisis-related policy measures and general regulations relating to the CDS market. The chronological evolution of events is shown in Appendix A.6. In the following, we discuss the impact of events in thematic subsections structured along the importance of our main empirical findings. We start with the analysis of the effectiveness of regulations such as the ban and the new ISDA rules. We then investigate the unconventional monetary policy of the ECB.

\subsection{The effect of regulatory actions}

\subsubsection{The large significant impact of the ban and the new ISDA rules}

There have been two important regulatory changes in the CDS market: the ban on short-selling uncovered sovereign CDS in 2012 and the market-led change to CDS trading resulting in new CDS definitions and standard reference obligations defined by the ISDA in 2014. ${ }^{17}$ Both of these regulations were successful in the sense that they succeeded in calming markets (reduced total connectedness) and in the case of the uncovered CDS ban in reducing speculation.

Starting with the discussion of the introduction of the new CDS definitions, we find a dramatic reduction in total connectedness in the left-hand panel of Figure 4 between the publication of the details of the rules (01.07.2014, marked by D) and their implementation (22.09.2014, marked by E). This reduction is strongly significant, as can be seen from the confidence intervals in the time series plot of total connectedness (left-hand panel of Figure 4). Disagregating the total connectedness into its individual components, country-wise connectedness, supports as expected this finding. The country-wise connectedness of all countries decreases strongly and almost synchronously (results are provided upon request). We can conclude that the new CDS rules have strongly and significantly reduced systemic risk and hence have been effective.

The permanent ban on outright short-selling of sovereign CDS contracts across all members of the European Economic Area (EU regulation 236/2012) was introduced in 2012 due to concerns that speculative behavior in the sovereign CDS market led to

\footnotetext{
${ }^{17}$ A big benefit of the new rules is the standardization of the reference obligation and hence a reduction of trade break risk. Furthermore, it removes potential basis risk between transactions that have the same reference entity but different reference obligations. The new rules also allow for consistent treatment of cleared and uncleared transactions.
} 
Figure 4: Evolution of connectedness linked to regulations in the CDS market

The figure shows the evolution of connectedness linked to the introduction of new CDS rules in 2014 (left-hand panel) and the ban of naked sovereign CDS in 2012 (right-hand panel). The right-hand panel shows the time evolution of total connectedness computed with CDS in red and with bond yields in blue. A 180 observations rolling window is used to compute the time series graph for total connectedness.
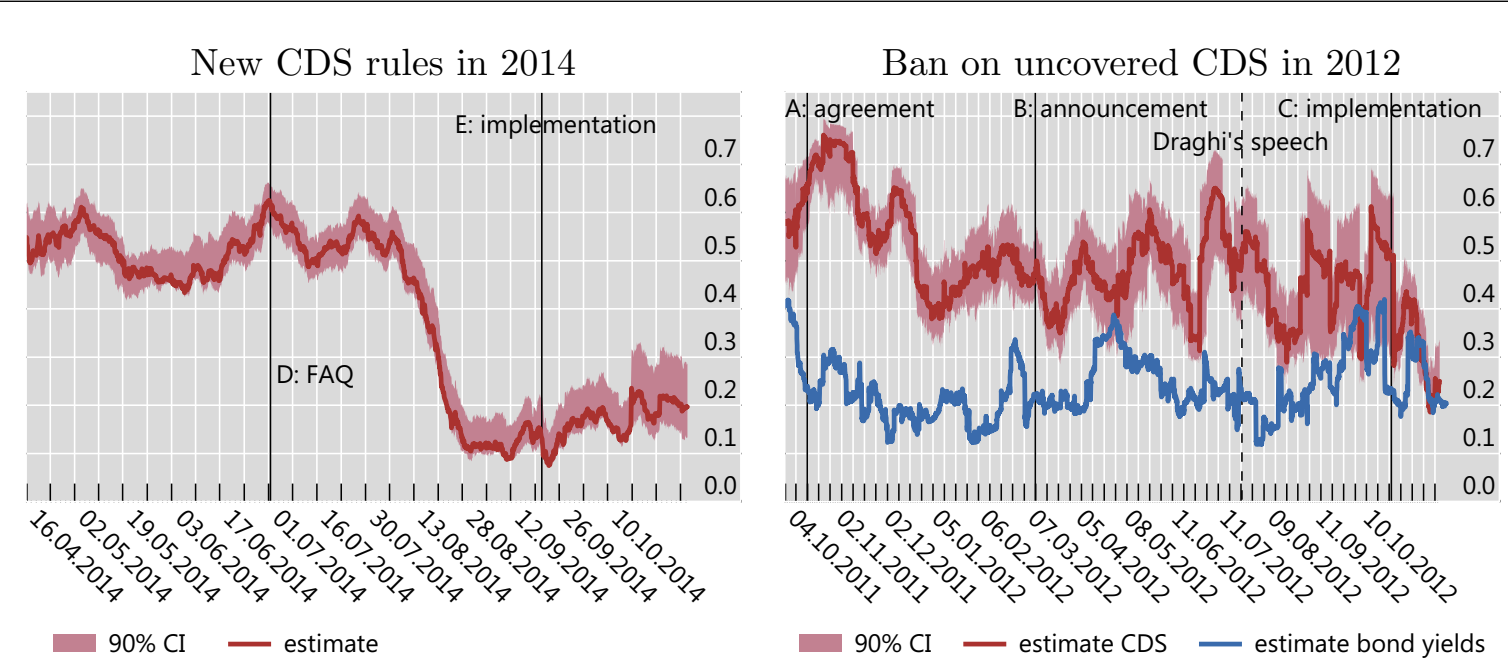

excessively high credit spreads in the most distressed countries. The period between the first agreement on the ban (18.10.2011, event A) and its implementation (01.11.2012, event C) covers a time span in which further important crisis-related events took place, such as Draghi's speech. In order to disentangle the effects of the CDS ban from other events we compare the connectedness measures of CDS spreads (in red in Figure 4) and bond yields ${ }^{18}$ (in blue in Figure 4). In particular, the fact that the credit situation of a sovereign entity can be inferred from both bonds or CDS, allows for identification of the impact of the ban since bonds are not directly affected by this CDS regulation. After it became clear that a permanent ban will be implemented (18.10.2011, denoted by A), we observe a significant decrease in CDS connectedness while connectedness based on bond yields remains at a steady level (0.1-0.4). Hence the ban was the driving force in reducing CDS connectedness. Figure 4 suggests only a slight impact of the Draghi speech on connectedness of both bond yields and CDS.

In order to assess the success of the ban in more detail, we examine country-wise behavior using CDS spreads in levels and country-wise connectedness in Figure 5. CDS spreads (left-hand panel of Figure 5) decrease most for Portugal and Ireland, the countries which were most affected by speculation (Greece as well, however the ISDA triggered a Greek default in 2012 and hence we do not consider Greece from 2012 onward). In Table 1 we present figures of net notional amounts outstanding CDS

18 We use 5-year zero coupon sovereign intraday bond yields from MTS. 
contracts divided by the amount of bonds traded on the MTS platform (as a proxy of bond market size) aggregated on annual frequency. We see that up to and including 2012 the CDS market grows faster than the bond market. However most importantly the growth is strongest for Greece, Ireland and Portugal, supporting our notion of strong speculations against these countries in the CDS market.

Table 1: CDS trading volume versus bond trading volume

The table presents annually aggregated net notional amounts of CDS outstanding based on weekly DTCC data devided by aggregated bond trading volumes based on tick-by-tick data from MTS.

\begin{tabular}{c|ccccccc}
\hline & France & Germany & Greece & Ireland & Italy & Portugal & Spain \\
\hline 2009 & 3.1 & 6.8 & 15 & 10.7 & 1.1 & 0 & 6.0 \\
2010 & 2.3 & 7.0 & 23.7 & 12.0 & 1.1 & 4.6 & 4.4 \\
2011 & 3.3 & 10.1 & 127.3 & 44.9 & 1.1 & 20.8 & 7.2 \\
2012 & 4.6 & 15.1 & & 85.4 & 1.4 & 27.2 & 6.9 \\
2013 & 2.7 & 7.3 & & 34.2 & 0.8 & 14.1 & 3.0 \\
2014 & 2.1 & 8.4 & & 5.5 & 0.5 & 1.5 & 1.5 \\
\hline
\end{tabular}

In line with our above reasoning we also find consistently that country-wise connectedness shown in the right-hand panel of Figure 5 for Ireland and Portugal falls most ${ }^{19}$ While country-wise connectedness of France, Germany, Italy and Spain remain rather unchanged after the announcement of the ban, the connectendess of Ireland and Portugal decreases quickly, suggesting that speculators left the market as intended by the ban. This behavior is in contrast to the time evolution of country-wise connectedness after the CDS rules in 2014, where the individual connectedness of all entities react equally strong and almost synchronously 20 Clearly, the provided evidence together with the statistical significance suggest that the ban was successful in reducing speculation and systemic risk. Our findings are in line with Che and Sethi (2014) and also support the early call of a ban of naked sovereign CDS from Portes (2010).

\subsubsection{No pure liquidity story}

Despite the positive impact of CDS regulations shown above, there have also been concerns about negative side-effects on liquidity (see, e.g. Duffie, 2010). It is a common belief that the results presented above can be entirely explained through liquidity

\footnotetext{
19 Country-wise connectedness is represented by averages of Ireland and Portugal in green and for the other countries in blue for graphical clarity. A graph with each country-wise connectedness shown individually can be provided upon request.

20 A graph of the behaviour of individual connectedness is provided upon request.
} 
Figure 5: Evolution of CDS levels and clustered countrywise connectedness

The figure illustrates CDS levels and clustered country-wise conectedness: one cluster contains Portugal and Ireland, the other cluster France, Germany, Italy and Spain.

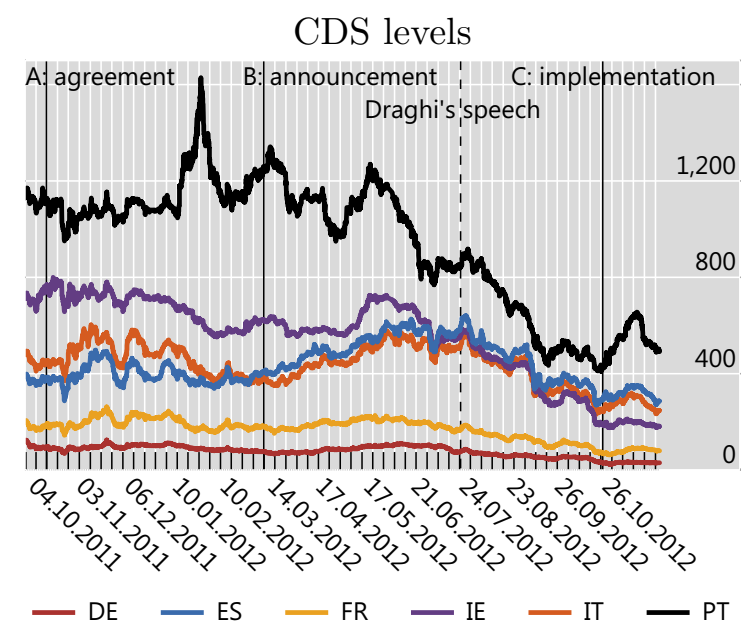

Clustered countrywise connectedness

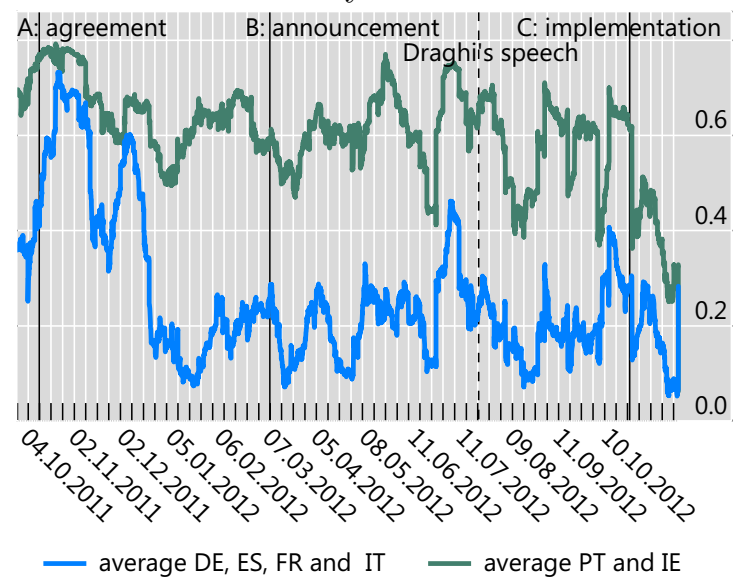

leading to reduced price informativeness (see, e.g. Silva et al., 2016), in a sense that the CDS market has dried out and does not price credit risk efficiently after the ban.

Since CDS are traded over-the-counter (OTC), it is challenging to measure liquidity reliably. However, with the available data we find no signals that the CDS market for sovereign CDS dried out due to the ban or the new ISDA definitions. This is illustrated by the relative bid-ask spreads in Figure 6 which only increase modestly around the regulatory interventions. Our finding that the ban had no compelling impact on liquidity is in line with the ESMA final report 2013/614 and shows that the allowance to trade naked sovereign CDS for market making worked as intended. The left-hand panel of Figure 6 shows a slight decrease of liquidity beginning after the Draghi speech and ending with the implementation of the ban. This is an indication that both Draghi's speech and the ban have reduced speculation. A further indication of less speculation against the most distressed countries is the increase of Portuguese bid-ask spreads after the announcement of the ban (in between events A and B).

Across the entire sample between 2009 and 2014, the relative bid-ask spreads (Figure 15 in Appendix A.4 only change moderately. ${ }^{21}$ This evidence for a rather stable liquidity is confirmed by comparing two further proxies for liquidity: net notional amounts outstanding and number of trade counts. Although volume of net notional amounts outstanding slightly decreases from 2011 onwards, trade counts showed an upward trend, indicating increased market activity (see Figure 16 in Appendix A.4.

${ }^{21}$ Liquidity increases in 2009 due to the introduction of the first clearing houses and standardization of contracts. The ISDA "Big Bang Protocol" has increased transparency and market integration and hence increased market activity. 
Hence, our findings with regard to connectedness or systemic risk cannot be explained by a simple liquidity argument only. Thus, with the combined evidence of Subsection 4.1.1 and 4.1.2 we conclude that the ban and the ISDA regulations were successful.

Figure 6: Evolution of liquidity around the ban in 2012 and the ISDA regulations in 2014

The figure illustrates the time evolution relative CDS bid ask-spreads for individual countries.

Ban of trading naked sovereign CDS

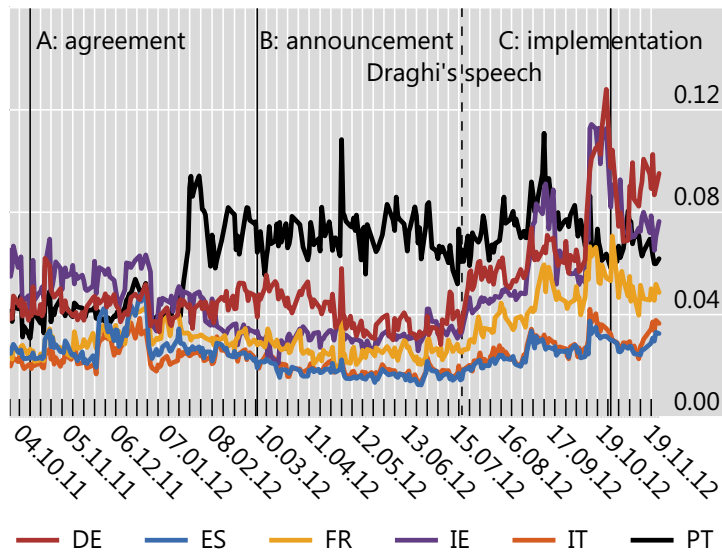

Introduction of new CDS rules

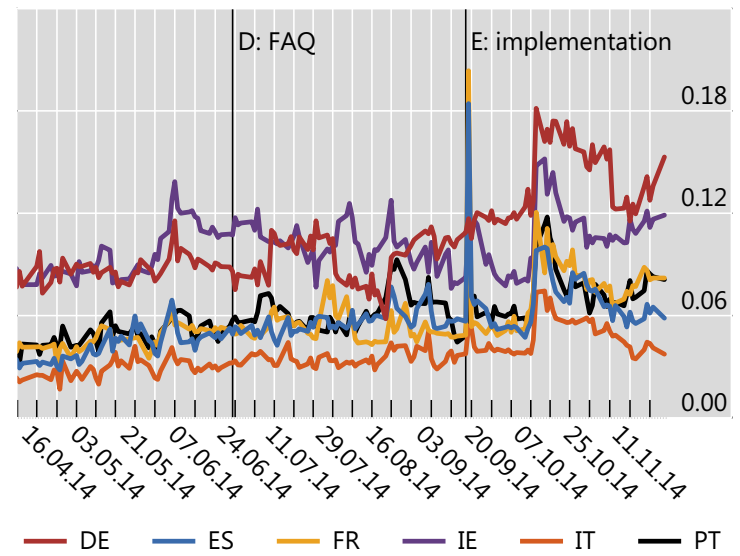

\subsection{The effect of unconventional monetary policies}

During the European sovereign debt crisis, several policy interventions targeted a specific country, e.g. the bailouts for Greece, Ireland, Portugal and the Spanish banks (events 1, 3, 4, 5 and 8 in Figure 2). Furthermore, there have been ECB-programs for the entire euro area, namely the Securities Markets Program (SMP) (events 2 and 6 in Figure 2) and the Outright Monetary Transactions (OMT) which were announced by Draghi's speech "whatever it takes" (event 9 in Figure 2).

\subsubsection{Public learning diminishes effectiveness}

Public learning dynamics about unconventional policy measures influence their impact. This is true for both country-specific bailouts as well as the European-wide SMP.

Generally, we find that the impact of sovereign bailouts decreased progressively. The Greek bailout in 2010 was the first of its kind. As it came as a surprise, because it undermined the Maastricht treaty, this unconventional policy had a strong effect (see Figure 8). When comparing the two consecutive bailouts of Ireland and Portugal respectively (total connectedness around these events are shown in Figure 7) we observe weaker effects. After financial aid for Ireland was decided, total connectedness 
decreased significantly. However, the Portuguese bailout six months later seems to have no impact on connectedness. The shrinking effectiveness of bailouts on stability was counteracted when a second EAP for Greece was discussed 22 The second bailout of Greece was linked to an enormous increase in the European Financial Stability Facility (EFSF) from $€ 440 \mathrm{bn}$ to $€ 780 \mathrm{bn}$. Unconventional policies remain effective as long as they stay unconventional, otherwise the size of the intervention needs to increase in order to ensure their effectiveness. Accordingly and in contrast to the Portuguese financial aid package, we see an effect of the second Greek EAP on total connectedness in Figure 9

Figure 7: Evolution of systemic risk, evidence from the Irish and Portuguese EAP

The graphs show the evolution of total connectedness around the bailouts. The grey area in the left and middle panel designates the time period in which the effect of an event is included in the rolling windows following the event.

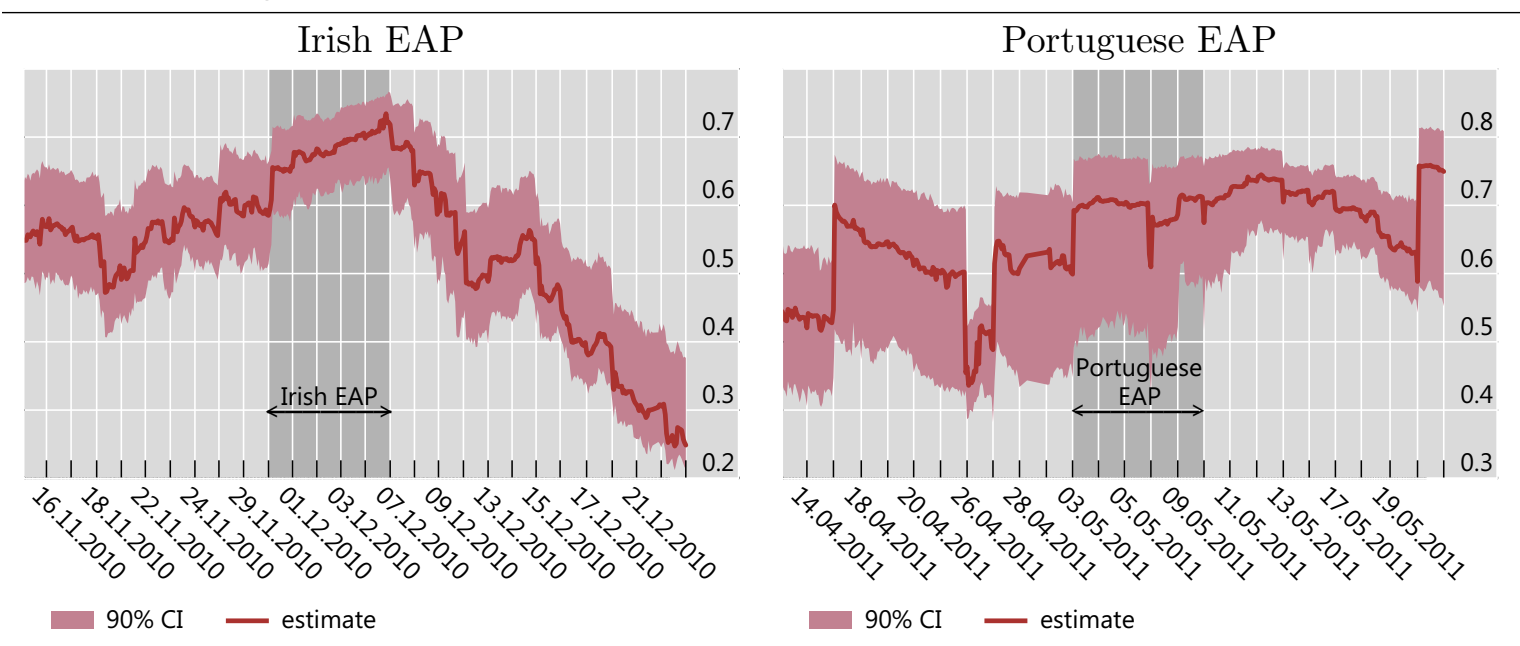

Similarly to increasing the scope of the EFSF for the second Greek bailout, the amount of bonds bought within the second round of the SMP was by far larger than during its first implementation. The second wave of the SMP, despite being more aggressive than the first SMP, was only able to level out total connectedness (see Figure 9). In contrast to this, the first wave of the bond purchases within the SMP was able to significantly reduce systemic risk and CDS levels (see Figure 8). This confirms reduced effectiveness of interventions over time for both European-wide as well as countryspecific unconventional policies, as also supported by the Lucas critique (Lucas, 1976). Market participants adjust their behavior with changes of decision makers' policies and regulations and price in any potential future intervention.

22 On 21.07.2011, the Euro Summit came to an agreement on a second bailout for Greece, just one day after Merkel and Sarkozy met to develop a common stance on Greece. 


\subsubsection{Impact of European-wide measures versus single country actions}

We show that European-wide interventions have a stronger and longer lasting impact than events which only target a particular country. One example for this is the first Greek bailout and the subsequent implementation of the SMP. CDS levels and connectedness around these events are shown in Figure 8. The key observation is that the effect of the Greek EAP was not sustainable while the SMP was able to reduce CDS spread levels and total connectedness.

On 28.04.2010 (beginning of the grey background in Figure 8) EU and IMF officials held crunch talks with German politicians, from which rumors of a $€ 120$ bn emergency package for Greece emerged. The levels of CDS spreads fell abruptly after this meeting but it had only a short-term effect. Despite the bailout for Greece agreed upon by the Eurogroup (03.05.2010, marked by the second dashed line in the graph) we observe a strong increase of CDS levels one day later. Total connectedness increased steadily during this period because the short-term effects were meaned out. While the bailout for Greece had a strong yet unsustainable effect, the SMP had a more lasting effect in the long run. On 09.05.2010 the ECB decided on the SMP, within which it started to buy large amounts of bonds on the secondary market the following day. Consequently, spread levels fell abruptly and to a larger extent than after the Greek EAP was agreed. The SMP was also successful in reducing connectedness, even though it does not significantly attain pre-event levels due to the revealed instability in Greece.

More than one year later, the same observation (of a higher effectiveness of Europeanwide interventions than country-specific measures) is made for the second Greek EAP and implementation of the SMP. Again, there is a longer lasting effect on reducing systemic risk due to the SMP as compared to the second Greek EAP. Connectedness drops after the bailout but soon increases again, whereby the second wave of the SMP generates a downward trend in systemic risk. Even though CDS levels react strongly after the second Greek bailout, they slightly raise afterwards again.

For Draghi's speech and the Spanish bailout, the picture is less clear as their close timely succession makes it hard to disentangle effects. Although total connectedness decreases after Draghi's speech (26.07.2012), the close sequence of the Spanish bailout (20.07.2012) and the speech does not allow to strictly separate the effect of the two events on connectedness. However, there is a decrease of CDS levels after Draghi's speech (first dashed line in Figure 10), whereas after the Spanish bank bailout CDS spreads rise (first solid line). This points to the more stabilizing effect of Draghi's promise to sustain the euro. Generally, changes in total connectedness are small and our bootstrapped confidence intervals indicate that these changes are not significant and thus not interpretable.

Thus generally for policy interventions, it is their scope which matters most for judging significance and persistence of their impact on systemic risk. 
Figure 8: First Greek EAP and SMP

The figure illustrates the time evolution of CDS spreads (left-hand panel) and total connectedness (middle panel) as well as two network graphs, showing individual connectedness. The grey area in the left and middle panel designates the time period in which the effect of an event is included in the rolling windows following the event. The upper network graph in the right-hand panel presents connectedness for the pre-event period (the event window contains five trading days, ending 28.04.2010 10:30) and the lower network graph for the post-event period (the event window contains five trading days, starting 14.05.2010 8:30).

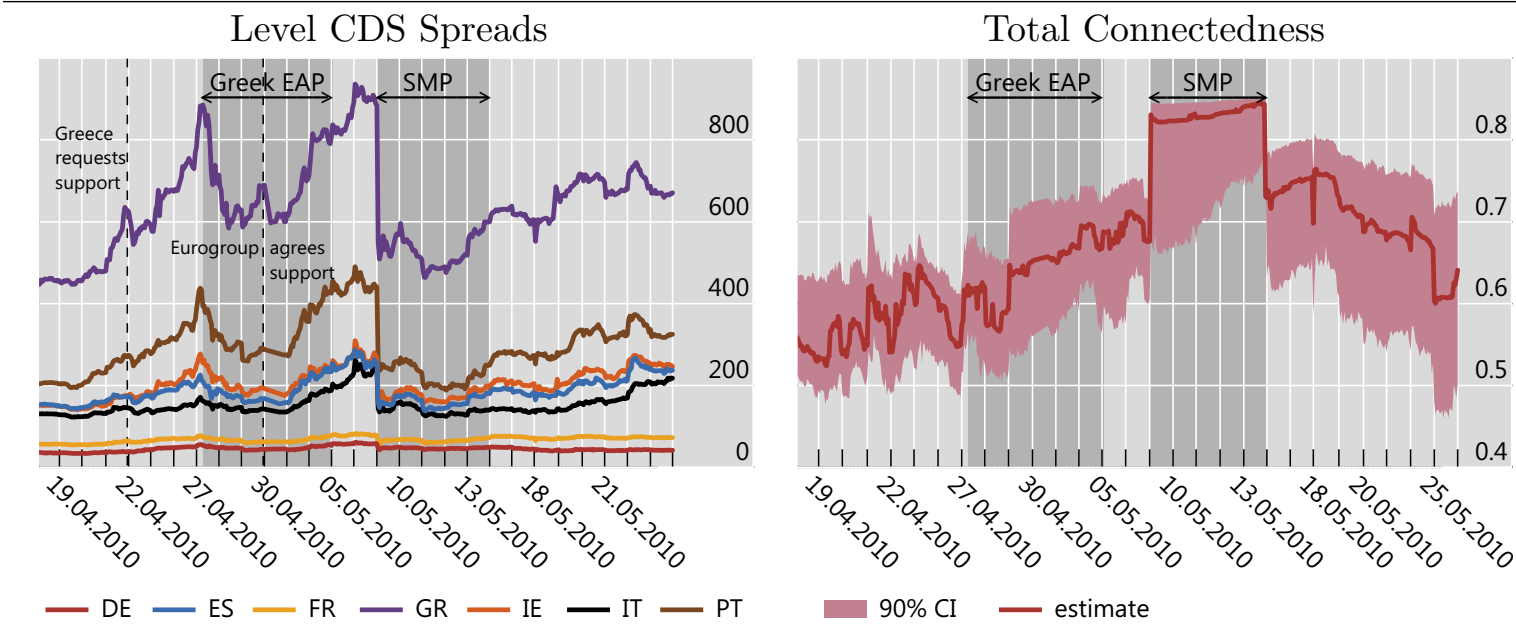

Figure 9: Second Greek EAP and second wave of SMP

For details concerning the figures we refer to Figure 8 . The pre-event period for the upper network graph ends 20.07.2011 17:30 and the post-event period for the lower network graph starts 12.08.2011 $8: 30$.

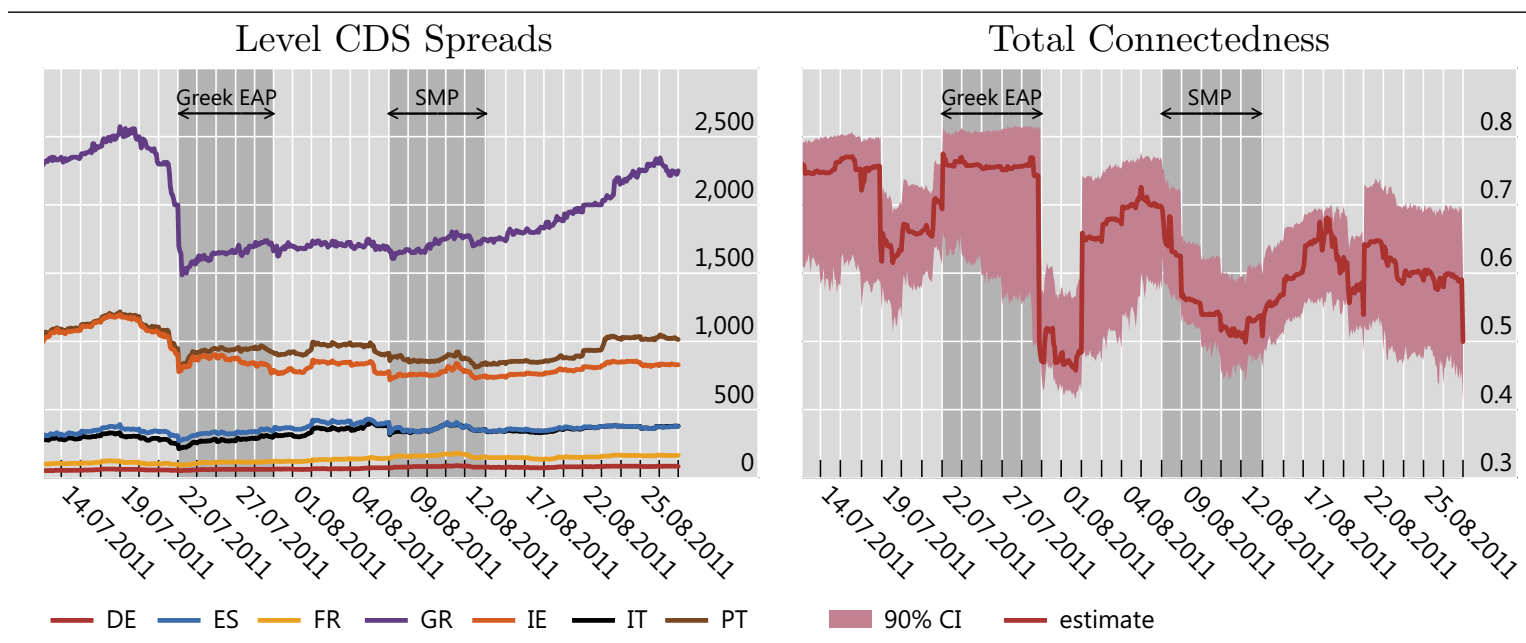

\subsubsection{No fragmentation of European sovereign credit risk}

We are the first to evaluate individual connectedness using intraday CDS data in order to analyze credit risk spillovers. Overall, we find balanced networks, in a sense that we do not observe fragmentation defined as a split-up of the network into independent 
Figure 10: Spanish bank bailout and Draghi speech

For details concerning the figures we refer to Figure 8. The pre-event period for the upper network graph ends 20.07.2012 17:30 and the post-event period for the lower network graph starts 01.08.2012 $8: 30$.

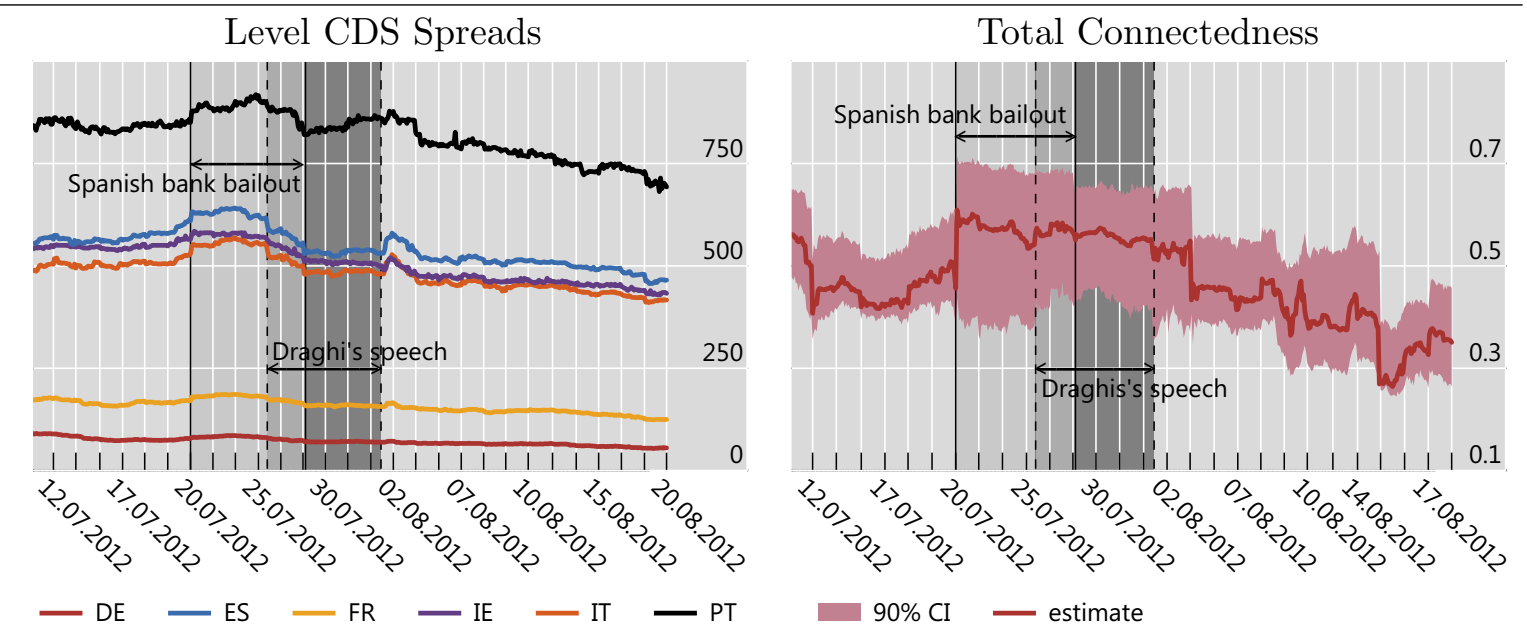

sub-networks (fragments) ${ }^{23}$ Also, we do not find a centering of an impaired country such as Greece in the network structure. This is in sharp contrast to existing studies using daily bond yields such as e.g Ehrmann and Fratzscher (2017) or Caporin et al. (2018) where the latter even find evidence for disintegration as still on-going at the end of their sample in April 2013. Though, in contrast to CDS spreads, the bond market was driven by flight-to-safety effects and hence was directly impacted by the SMP and OMT. Thus for assessing credit risk, CDS based measures are also generally considered as more suitable than bonds (see, e.g. Pan and Singleton, 2008, Ang and Longstaff, 2011). The advantage of CDS versus bonds in this context has also been documented empirically by a lead-lag behaviour (see, e.g. Buse and Schienle, 2019; Alter and Beyer, 2014).

Between the agreement of the permanent ban of naked sovereign CDS trading (end 2011) and the announcement of the technical details of the ban (beginning 2012) we observe a statistically significant drop of connectedness. This effect appears later than what is reported in networks using bond yields (see, e.g. Ehrmann and Fratzscher, 2017; Caporin et al., 2018). A possible reason for an earlier effect in networks based on bond yield data are the economic adjustment programs and the close supervision of these countries under bailout by the Troika as well as dry-out of bond trading in these impaired countries. It can be observed in the left-hand panel of Figure 11 that all countries become less connected during the period October 2011 to March 2010. Especially the volatility spillover channels for Ireland and Portugal with other countries

23 Ehrmann and Fratzscher (2017) define fragmentation as a reduction in credit risk spillovers, while we define fragmentation as used in colloquial language. 
weaken, however they become not disconnected or fragmented. Unlike Ehrmann and Fratzscher (2017) we do not find a segregation of Italy and Spain. On the contrary, Italy and Spain are equally connected to other countries (see left-hand panel of Figure 11).

We are the first to analyze changes in credit risk spillover induced by the new ISDA rules in 2014. The rules are implemented in September 2014 (marked E in Figure 11), however the technical details of the implementation are known to market participants already 01.07.2014 (marked D). Comparing the networks (see right-hand panel) we recognize a dramatic reduction in individual connectedness. We want to stress that the network graphs of the post implementation period do not show a fragmentation. Similar to the ban, the network remains balanced after the ISDA rules, however our results prove that the market-led regulations have been extraordinary successful in reducing credit risk spillovers.

Figure 11: Evolution of connectedness linked to the CDS ban and the new ISDA rules

The figure illustrates individual connectedness in form of network graphs including estimates (middle), lower confidence interval boundary (top) and upper confidence interval boundary (bottom). The network graphs are computed with five trading day windows. Nodes represent countries and arrows represent individual connectedness measures, e.g. an arrow from country $j$ to country $i$ visualizes $\widetilde{s}_{i j}$ (see Equation (1)). The width and colour of the connecting lines indicate the strength of the connectedness: bold red lines indicate strong connectedness (fourth quartile), orange lines indicate upper medium connectedness (third quartile), thin yellow line indicate lower medium connectedness (second quartile) and no connecting line indicates small connectedness (first quartile). The arrows at each line show the directedness of the connectedness.

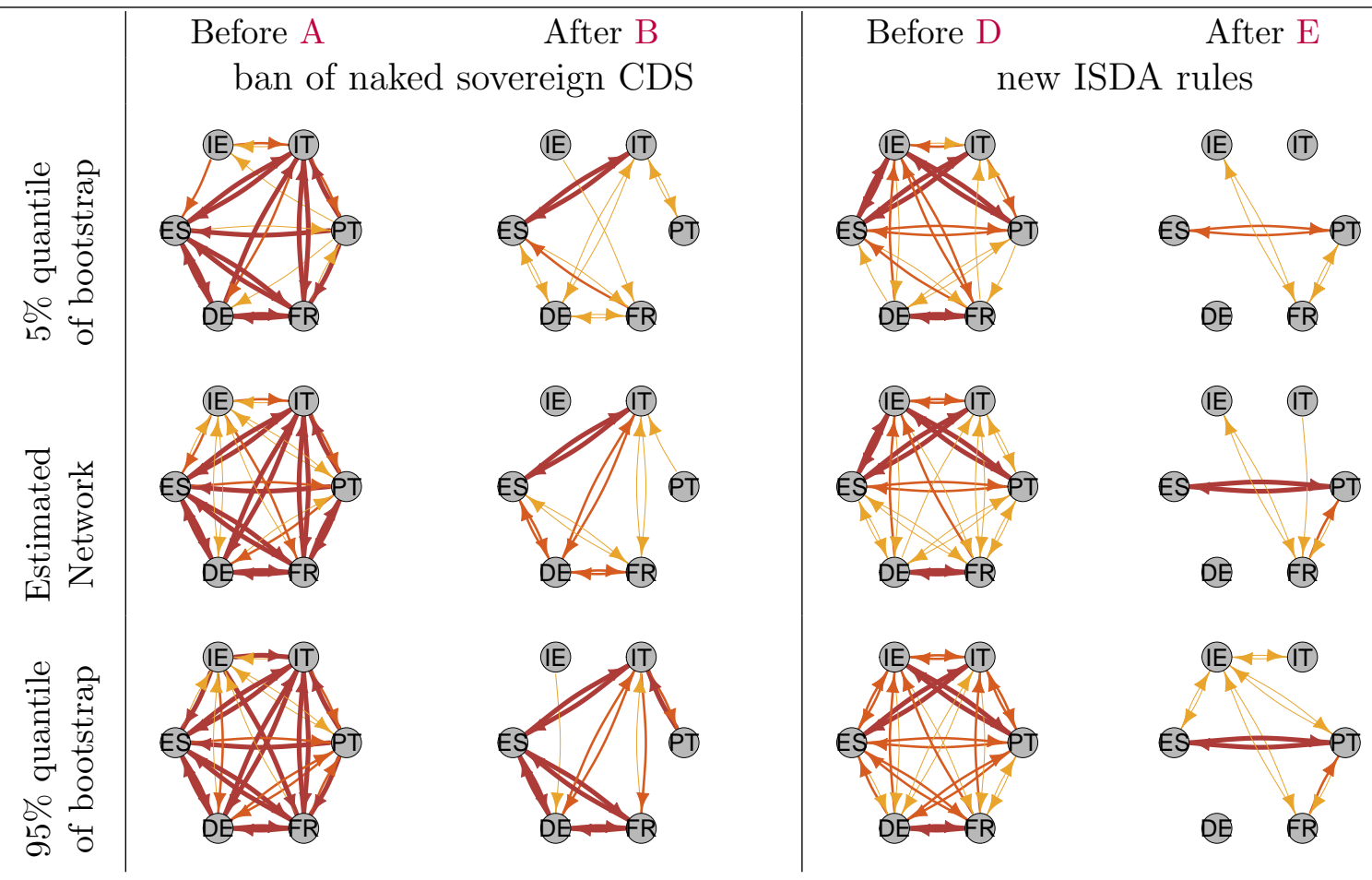


Figure 12: Evolution of connectedness linked to the Greek and Portuguese bailout

The figure illustrates individual connectedness in form of network graphs. For details we refer to Figure 11.

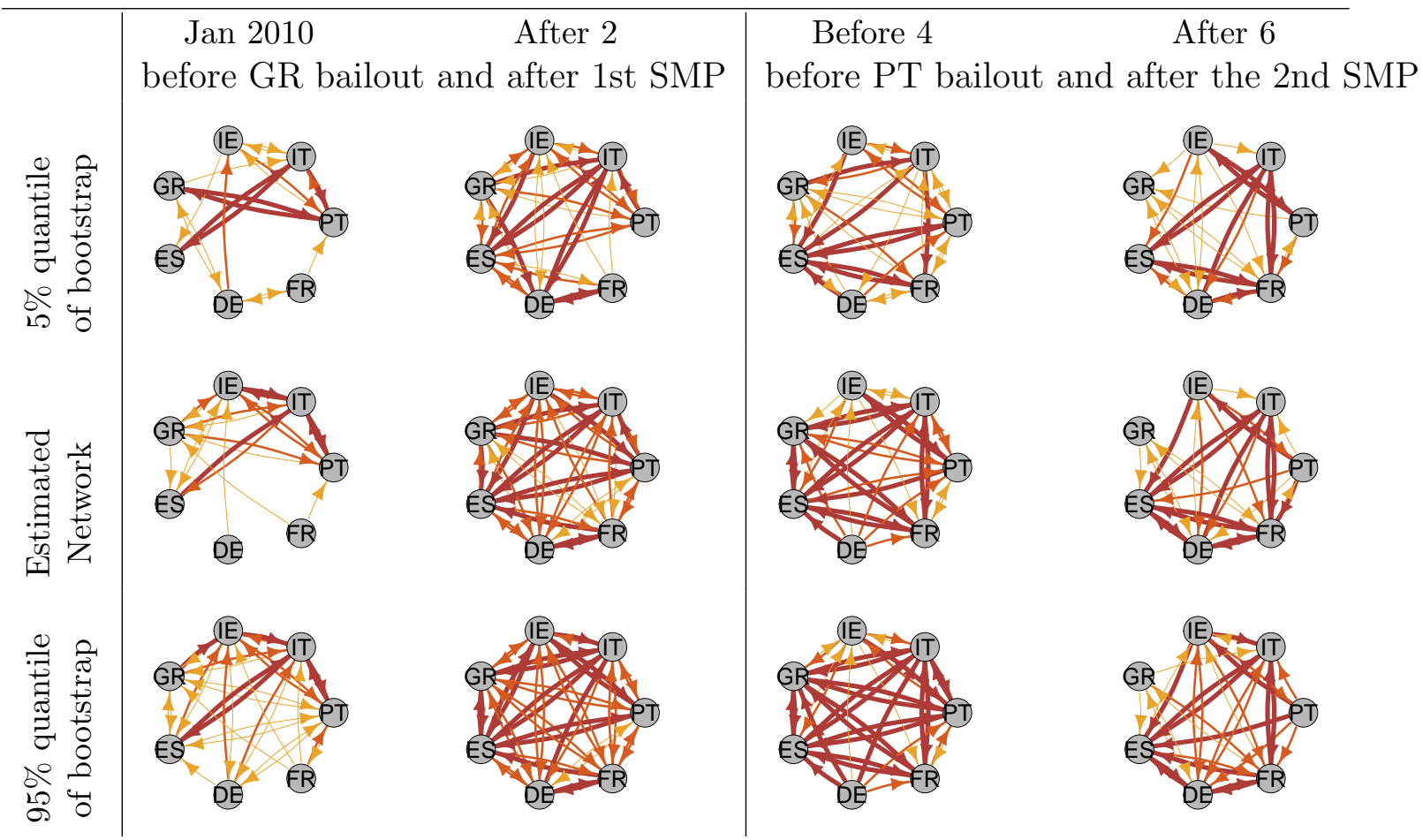

Connectedness rises dramatically between the end of 2009 and the first Greek bailout in April 2010, leading to a strong integration of the sovereign network. This increase at the beginning of the sovereign debt crisis is comparable to "wake-up call" contagion as identified for the bond market by Giordano et al. (2013). Before the first Greek bailout (a violation of the Maastricht treaty), we can see two groups of countries in the network (see left-hand panel in Figure 12). The first group consists of peripheral countries, which are strongly connected among each other. The second fragment consists of France and Germany, which are weakly connected with other countries. This observation is in contrast to results of Ehrmann and Fratzscher (2017) for bond markets. Our analysis clearly shows two effects on the network after the bailout and the SMP: It becomes more balanced or less fragmented and the high level of overall total connectedness decreases significantly in size (see Figure 8) at the expense of more spillover channels. This is because large countries such as France and Germany now also share credit risk of the crisis countries due to the bailout facility.

After the first Greek bailout and implementation of the SMP the structure of networks remains relatively stable throughout the crisis. The bailouts for Ireland and Portugal and the "whatever it takes" speech do not induce a significant change in individual volatility spillovers. Even though total connectedness decreases after Irelands bailout, the network connections mostly remain the same. Of all events during the cri- 
sis, volatility spillovers change most after the second Greek bailout and bond-buying within the SMP in 2011. However, only the decreasing connections of Italy with Portugal and Ireland were significant. Similarly, the only significant changes in the network structure after the first Greek bailout and SMP implementation in 2010 are between Germany and Italy and from Greece to Ireland ${ }^{24}$

An important exception to the unaltered networks is the isolation of Greece between the Portuguese bailout and the second Greek bailout and SMP implementation (see right-hand panel of Figure 12). Thanks to this isolation and the reduced exposure of financial intermediaries to Greece its (official) default on 09.03.2012 did not strongly affect other countries in the network.

\section{Conclusion}

The focus of the paper is the analysis of the effectiveness of regulations and policies during the euro area sovereign debt crisis, from beginning 2009 until end 2014. In our context, we define effectiveness as a statistical significant drop in connectedness between sovereign entities within the network. We have estimated connectedness based on variance decomposition and computed corresponding confidence intervals employing a bootstrap methodology to judge the statistical significance of our results. Our analysis rests on intraday sovereign CDS data. A key advantage of intraday data is that the large amount of observations enabled us to compute precise connectedness measures for a particular regulatory or policy event unblurred by other nearby events. The reason behind this advantage is that we can chose much smaller event windows in our analysis as compared to research based on daily data (e.g. Ehrmann and Fratzscher (2017) and Caporin et al. (2018)) .

We focused on two important regulations of the credit risk market, the ban on trading naked sovereign CDS in 2012 and the implementation of the new ISDA rules in 2014. We show that they have been important in reducing connectedness between European sovereigns. The new ISDA rules on CDS definitions and standard reference obligations resulted in a fast, strong and statistically significant reduction in connectedness. With respect to the ban, total connectedness reduced also strongly during the period of the announcement and the implementation. However, the period is rather lengthy and it was at the height of the crisis with many events taking place. Therefore, linking the reduction to the ban is not straightforward. By comparing connectedness measures based on bond data, which is affected by credit conditions, but not by the ban, we can conclude that the CDS ban was crucial for calming markets. Furthermore, by disentangling total connectedness into its components, we have found that Irish and Portuguese connectedness dropped most. Ireland and Portugal were most affected by

${ }^{24}$ The relevant network graphs are provided upon request. 
speculation. Hence, we can conclude that the ban on uncovered CDS was effective and especially successful in reducing speculation for Ireland and Portugal. The ban and the new ISDA rules had some moderate adverse impact on liquidity, however far from the fear that the markets may dry out and lead to an inferior CDS market for single name sovereign CDS. With respect to volatility spillovers between sovereign CDS, the regulations seemed to be more important than other interventions such as Draghi's speech.

A key finding of our analysis is that the economic adjustment programs for Greece, Ireland and Portugal were able to reduce systemic risk only for a short period, until negative market perceptions bounced back. Euro-wide programs such as the SMP had a longer lasting and stronger effect. Furthermore, the effect of an unconventional policy measure diminishes when it is implemented more than once. The decreasing effectiveness can be counteracted by an increase in the size of the intervention. Before, the second Greek economic adjustment program, the bailout facility was drastically enlarged in order to counteract the reduced effectiveness.

Finally, we do not observe fragmentation in European sovereigns credit markets. The networks are balanced and there was no single source of contagion in a sense of a central node network. After the start of the second SMP we see that Greece is slightly isolated, which can be judged as one reason why the latter Greek default did not impact the network.

The analyzed events indicate that the implemented active policy and regulatory measures helped to substantially reduce the impact of the European debt crisis. Here in particular, regulatory actions played a key role producing sustainable effects in contrast to monetary policy measures where the effect was only short-term and vanished over time. Thus in severe crisis situations, monetary policy actions can only pave the way until regulatory adjustments are taken and do not provide a long-term solution in themselves. 


\section{References}

A.Chan-Lau, J. (2017): "Variance Decomposition Networks: Potential Pitfalls and a Simple Solution," IMF Working Papers 17/107, International Monetary Fund.

Ahelegbey, D. F., M. Billio, And R. Casarin (2016): "Bayesian Graphical Models for STructural Vector Autoregressive Processes," Journal of Applied Econometrics, 31, 357-386, jae.2443.

Alter, A. And A. Beyer (2014): "The dynamics of spillover effects during the European sovereign debt crisis," Journal of Banking and Finance, 134-153.

Ang, A. And F. Longstaff (2011): "Systemic sovereign credit risk: Lessons from the US and Europe," NBER Working Papers 16983, National Bureau of Economic Research, Inc.

Arghyrou, M. And A. Kontonikas (2012): "The EMU sovereign-debt crisis: Fundamentals, expectations and contagion," Journal of International Financial Markets, Institutions and Money, 22, 658-677.

Beber, A. And M. Pagano (2013): "Short-Selling Bans Around the World: Evidence from the 2007-09 Crisis," Journal of Finance, 68, 343-381.

Betz, F., N. Hautsch, T. A. Peltonen, And M. Schienle (2016): "Systemic risk spillovers in the European banking and sovereign network," Journal of Financial Stability, 25, $206-224$.

Blatt, D., B. Candelon, And H. Manner (2015): "Detecting contagion in a multivariate time series system: An application to sovereign bond markets in Europe," Journal of Banking \& Finance, 59, 1-13.

Buse, R. And M. Schienle (2019): "Measuring Connectedness of Euro Area Sovereign Risk," International Journal of Forecasting, 25, 25-44.

Caporin, M., L. Pelizzon, F. Ravazzolo, and R. Rigobon (2018): "Measuring sovereign contagion in Europe," Journal of Financial Stability, 34, 150 - 181.

Che, Y.-K. And R. Sethi (2014): "Credit market speculation and the cost of capital," American Economic Journal, 6, 1-34.

Chu, C.-S. J., K. Hornik, And C.-M. KAUn (1995): "MOSUM tests for parameter constancy," Biometrika, 82, 603-617.

Claeys, P. And B. VAŠŚC̆EK (2012): "Measuring Sovereign Bond Spillover in Europe and the Impact of Rating News," Working Papers 2012/07, Czech National Bank, Research Department. 
(2014): "Measuring Bilateral Spillover and Testing Contagion on Sovereign Bond Markets in Europe," Working Papers 1666, European Central Bank.

Daniels, K. N. And M. S. Jensen (2005): "The Effect of Credit Ratings on Credit Default Swap Spreads and Credit Spreads," The Journal of Fixed Income, 15, 16-33.

Diebold, F. And K. Yilmaz (2009): "Measuring Financial Asset Return and Volatility Spillovers, with Application to Global Equity Markets," Economic Journal, 119, 158-171.

Diebold, F. X. AND K. Yilmaz (2014): "On the network topology of variance decompositions: Measuring the connectedness of financial firms," Journal of Econometrics, 182, 119-134.

Duffie, D. (2010): "Is there a case for banning short speculation in sovereign bond markets?" Financial Stability Review, 55-59.

Ehrmann, M. And M. Fratzscher (2017): "Euro area government bonds Fragmentation and contagion during the sovereign debt crisis," Journal of International Money and Finance, 70, $26-44$.

Engle, R. (1982): "Autoregressive Conditional Heteroscedasticity with Estimates of the Variance of United Kingdom Inflation," Econometrica, 50, 987-1007.

Engle, R., E. Jondeau, And M. Rockinger (2014): "Systemic Risk in Europe," Review of Finance, 1-46.

Eser, F. And B. SchwaAB (2016): "Evaluating the impact of unconventional monetary policy measures: Empirical evidence from the ECBs Securities Markets Programme," Journal of Financial Economics, 119, 147-167.

FAlagiarda, M. AND S. Reitz (2015): "Announcements of ECB unconventional programs: Implications for the sovereign spreads of stressed euro area countries," Journal of International Money and Finance, 53, 276 - 295.

Ghysels, E., J. Idier, S. Manganelli, And O. Vergote (2014): "A high frequency assessment of the ECB securities markets programme," Working Paper Series 1642, European Central Bank.

Ghysels, E., A. Sinko, And R. VAlkanov (2007): "MIDAS regressions: Further results and new directions," Econometric Reviews, 26, 53-90.

Gibson, H. D., S. G. Hall, and G. S. Tavlas (2016): "The effectiveness of the ECB's asset purchase programs of 2009 to 2012," Journal of Macroeconomics, 47, 45 - 57, what Monetary Policy Can and Cannot Do. 
Giordano, R., M. Pericoli, and P. Tommasino (2013): "Pure or Wake-upCall Contagion? Another Look at the EMU Sovereign Debt Crisis," International Finance, 16, 131-160.

Gyntelberg, J., P. Hoerdahl, K. Ters, and J. Urban (2013): "Intraday dynamics of euro area sovereign CDS and bonds," BIS Working Papers 423, Bank for International Settlements.

(2017): "Arbitrage costs and the persistent non-zero CDS-bond basis: Evidence from intraday euro area sovereign debt markets," BIS Working Papers 631, Bank for International Settlements.

(2018): "Price discovery in euro area sovereign credit markets and the ban on naked CDS," Journal of Banking and Finance, 96, 106-125.

Hamilton, J. D. (1994): Time Series Analysis, Princeton Universiy Press.

Hautsch, N., J. Schaumburg, and M. Schienle (2015): "Financial Network Systemic Risk Contributions," Review of Finance, 19, 685-738.

Kiesel, F., F. LüCKE, And D. Schiereck (2015): "Regulation of uncovered sovereign credit default swaps evidence from the European Union," The Journal of Risk Finance, 16, 425-443.

Koop, G., M. H. Pesaran, and S. M. Potter (1996): "Impulse response analysis in nonlinear multivariate models," Journal of Econometrics, 74, 119-147.

KuAn, C.-M. And K. Hornik (1995): "The generalized fluctuation test: A unifying view," Econometric Reviews, 14, 135-161.

LütKePohl, H. (2000): Bootstrapping impulse responses in VAR analyses, Heidelberg: Physica-Verlag HD, 109-119.

(2006): New Introduction to Multiple Time Series Analysis, Springer.

NeIL, B. And J.-F. Fillion (1999): "An Intraday Analysis of the Effectiveness of Foreign Exchange Intervention," Staff Working Papers 99-4, Bank of Canada.

Oenmke, M. And A. Zawadowski (2015): "Synthetic or Real? The Equilibrium Effects of Credit Default Swaps on Bond Markets," The Review of Financial Studies, 28, 3303-3337.

Pan, J. And K. Singleton (2008): "Default and recovery implicit in the term structure of sovereign CDS spreads." The Journal of Finance, 63, 2345-84. 
Pesaran, H. H. And Y. Shin (1998): "Generalized impulse response analysis in linear multivariate models," Economics Letters, 58, 17-29.

Portes, R. (2010): "Ban Naked CDS," Eurointelligence.

Silva, P. P., C. Vieira, And I. Vieira (2016): "The EU Ban on Uncovered Sovereign Credit Default Swaps: Assessing Impacts on Liquidity, Volatility, and Price Discovery," The Journal of Derivatives, 23, $74-98$.

Ters, K. And J. URBAn (2016): "Intraday dynamics of euro area sovereign credit risk contagion," BIS Working Papers 573, Bank for International Settlements. 


\section{A Appendix}

\section{A.1 Descriptive Statistics}

The descriptive statistics of the intraday CDS data is presented in Table 2. We have split the data in 5 periods, within which we have found similar statistical behavior. The first period covers the entire year 2009 and the second period starts in 2010 and ends on the 18.10.2011, when it became clear that the anticipated ban of uncovered sovereign CDS will become permanent. The third period ends in December 2012 and contains the discussion period on how the ban should look like in detail and the implementation of the ban. The fourth period starts in January 2013 and lasts until end of June 2014. This period contains the consultation period and announcement of the important changes on credit derivatives definitions and standard reference obligations, which became effective on the 22.09.2014 and which falls in our last period.

We report the mean, median and standard deviation as well as the mean bid-ask spread and the average number of observations. The mean and median reported in Table 2 are consistent with the timeseries plots in Figure 1. The standard deviation growth as expected with the mean/median. We furthermore measure the changes within a day relative to the changes from one day to the next by comparing mean absolute differences (MAD) in a ratio ${ }^{25}$ A ratio smaller than 1 shows that the data varies less within one day than across days. This is almost always the case, with exception of Germany, France and Ireland in 2013 and 2014. While we have almost noempty timestamps in 2010-2012 we recognize that data availability slightly decreased in 2013 and more in 2014, which is reported in the average number of observations per day in Table 2 .

We have also analyzed the first differences of CDS spreads and have found that the mean and the median of the first differences are around zero. The standard deviation is in the order of one, with slightly larger values for the crisis countries. The standard deviation for Greece in the second period is largest and equal to 14.32 .

Results on the unit root and stationarity tests are presented in Table 3 for levels and first differences. We conclude that all series are integrated of order one.

\section{A.2 Robustness with Respect to Data Specifics}

As mentioned in Section 2 and shown in Appendix A.1, the intraday dataset is characterized by two specifics: smaller number of observations in 2009 and second half

\footnotetext{
${ }^{25}$ For robustness reasons, we consider averages of the first and second half of one day, which we denote by $\bar{d}_{t}^{1}$ and $\bar{d}_{t}^{2}$, respectively. Intraday MAD is then computed by $\sum_{t \in T}\left|\bar{d}_{t}^{2}-\bar{d}_{t}^{1}\right|$ and inter-day MAD is computed by $\sum_{t \in T}\left|\bar{d}_{t+1}^{1}-\bar{d}_{t}^{2}\right|$. The ratio, intraday MAD divided by inter-day MAD shows how much the data varies within one day compared to across days.
} 
Table 2: Descriptive statistics of intraday CDS spreads

The table presents a detailed descriptive statistics for five periods, for which we have found similar statistical behaviour of the CDS levels. The mean, median and standard deviation (std dev) is reported, as well as the ratio of mean absolute difference (MAD) of intraday and inter-day level changes. Further, the mean of the bid-ask spread and the average number of observations per day is reported. No figures are shown for the last three periods for Greece because of the Greek restructuring.

\begin{tabular}{|c|c|c|c|c|c|c|}
\hline & & 1.1.09-31.12.09 & $1.1 .10-18.10 .11$ & 19.10.11-31.12.12 & 1.1.13-30.6.14 & $1.7 .14-31.12 .14$ \\
\hline \multirow{6}{*}{ 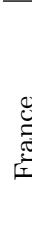 } & Mean & 41.92 & 87.46 & 162.90 & 63.41 & 46.76 \\
\hline & Median & 35.58 & 78.75 & 175.50 & 64.94 & 45.87 \\
\hline & Standard deviation & 20.85 & 36.03 & 48.17 & 13.90 & 5.70 \\
\hline & MAD intra/inter ratio & 0.38 & 0.17 & 0.20 & 1.47 & 1.59 \\
\hline & Mean bid-ask-spread & 0.11 & 0.04 & 0.03 & 0.04 & 0.07 \\
\hline & Average obs/day & 14.49 & 17.82 & 17.55 & 16.72 & 15.02 \\
\hline \multirow{6}{*}{ 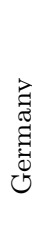 } & Mean & 38.64 & 48.45 & 74.78 & 28.01 & 20.84 \\
\hline & Median & 33.33 & 43.12 & 80.97 & 25.33 & 20.75 \\
\hline & Standard deviation & 19.74 & 17.62 & 24.45 & 6.91 & 2.28 \\
\hline & MAD intra/inter ratio & 0.38 & 0.22 & 0.24 & 2.01 & 2.09 \\
\hline & Mean bid-ask-spread & 0.11 & 0.06 & 0.05 & 0.08 & 0.12 \\
\hline & Average obs/day & 14.42 & 17.73 & 17.50 & 16.64 & 14.98 \\
\hline \multirow{6}{*}{ 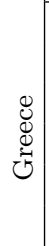 } & Mean & 172.00 & 960.53 & & & \\
\hline & Median & 154.16 & 863.06 & & & \\
\hline & Standard deviation & 54.55 & 524.13 & & & \\
\hline & MAD intra/inter ratio & 0.29 & 0.21 & & & \\
\hline & Mean bid-ask-spread & 0.05 & 0.04 & & & \\
\hline & Average obs/day & 15.18 & 17.64 & & & \\
\hline \multirow{6}{*}{ 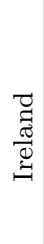 } & Mean & 203.06 & 476.85 & 521.62 & 128.42 & 55.52 \\
\hline & Median & 184.33 & 537.35 & 575.89 & 136.83 & 54.50 \\
\hline & Standard deviation & 65.34 & 247.53 & 186.00 & 41.72 & 5.21 \\
\hline & MAD intra/inter ratio & 0.28 & 0.20 & 0.28 & 1.14 & 1.88 \\
\hline & Mean bid-ask-spread & 0.05 & 0.04 & 0.05 & 0.07 & 0.11 \\
\hline & Average obs/day & 15.18 & 17.87 & 17.44 & 16.86 & 15.14 \\
\hline \multirow{6}{*}{$\stackrel{\vec{\varpi}}{\stackrel{\Xi}{ \pm}}$} & Mean & 108.72 & 202.93 & 422.43 & 204.81 & 115.88 \\
\hline & Median & 94.75 & 177.62 & 437.55 & 229.50 & 111.00 \\
\hline & Standard deviation & 40.86 & 94.67 & 94.21 & 61.33 & 20.32 \\
\hline & MAD intra/inter ratio & 0.29 & 0.16 & 0.19 & 0.47 & 0.90 \\
\hline & Mean bid-ask-spread & 0.05 & 0.03 & 0.02 & 0.02 & 0.04 \\
\hline & Average obs/day & 15.23 & 17.86 & 17.59 & 17.35 & 15.67 \\
\hline \multirow{6}{*}{ 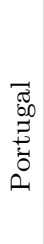 } & Mean & 80.71 & 492.75 & 911.46 & 338.43 & 188.28 \\
\hline & Median & 72.75 & 432.45 & 1033.13 & 362.50 & 191.83 \\
\hline & Standard deviation & 28.54 & 294.02 & 284.25 & 107.28 & 23.79 \\
\hline & MAD intra/inter ratio & 0.29 & 0.19 & 0.35 & 0.50 & 0.69 \\
\hline & Mean bid-ask-spread & 0.06 & 0.04 & 0.06 & 0.04 & 0.07 \\
\hline & Average obs/day & 14.86 & 17.87 & 16.75 & 17.03 & 15.36 \\
\hline \multirow{6}{*}{ 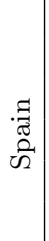 } & Mean & 93.68 & 245.05 & 429.43 & 191.06 & 83.07 \\
\hline & Median & 87.70 & 238.50 & 405.88 & 214.60 & 78.00 \\
\hline & Standard deviation & 27.37 & 80.80 & 92.10 & 71.86 & 17.07 \\
\hline & MAD intra/inter ratio & 0.27 & 0.18 & 0.19 & 0.54 & 0.93 \\
\hline & Mean bid-ask-spread & 0.05 & 0.03 & 0.02 & 0.03 & 0.06 \\
\hline & Average obs/day & 15.04 & 17.87 & 17.60 & 17.31 & 15.69 \\
\hline
\end{tabular}


Table 3: Unit root and stationarity tests for CDS data - 2009-2014

The table reports the statistics of unit root and stationarity tests for the period from January 2009 to December 2014. The null hypothesis of the ADF and PP test is: the data has a unit root. For the KPSS test, the null is stationarity, and the $0.01,0.05$ and 0.10 critical values for the test statistics are $0.739,0.463$ and 0.347 , respectively.

\begin{tabular}{|l|c|c|c|c|c|c|}
\hline & \multicolumn{3}{|c|}{ levels } & \multicolumn{3}{c|}{ first differences } \\
\hline Sovereign & $p_{\text {ADF }}$ & $p_{\text {PP }}$ & KPSS stat. & $p_{\text {ADF }}$ & $p_{\text {PP }}$ & KPSS stat. \\
\hline France & 0.40 & 0.53 & 4.74 & 0.00 & 0.00 & 0.09 \\
Germany & 0.25 & 0.43 & 3.71 & 0.00 & 0.00 & 0.36 \\
Greece & 1.00 & 1.00 & 14.31 & 0.00 & 0.00 & 0.65 \\
Ireland & 0.76 & 0.77 & 5.21 & 0.00 & 0.00 & 0.25 \\
Italy & 0.48 & 0.35 & 6.23 & 0.00 & 0.00 & 0.17 \\
Portugal & 0.96 & 0.89 & 6.23 & 0.00 & 0.00 & 0.26 \\
Spain & 0.21 & 0.25 & 6.24 & 0.00 & 0.00 & 0.17 \\
\hline
\end{tabular}

of 2014 (see Table 2), as well as a higher intraday variance for France, Germany and Ireland from 2013 onwards.

First, we assess if a reduced number of observations as in 2009 or in the second half of 2014 affects the connectedness measure. To this end, we gather the structure of missing values from July to December 2014 and delete these values for the subsample covering July to December 2010 (amounting to 183 deleted observations of a total of 2,231 observations). The connectedness measures based on the original subsample of 2010 are similar to those based on the same subsample with deleted values, as can be seen in the left-hand panel of Figure 13 . Thus we conclude that the relatively low connectedness in 2009 and the drop of connectedness in 2014 is not due to a lower number of observations.

Second, a similar, yet more complex approach, is applied to verify the robustness with respect to higher intraday variance as in Germany, France and Ireland from 2013 onward. In order to assess if this change in variance affects the resulting connectedness measures, we construct a second dataset of the first half of 2013 with a similar intraday variance as in the first half of $2012{ }^{26}$ To this end, we extract daily variances for the first half of 2012. The intraday values of 2013 are then replaced by their own mean plus a random draw of a normally distributed variable with zero mean and variance of the same day in 2012. We see that the total connectedness based on the dataset with a similar variance structure as in 2012 is much lower than the connectedness measure

26 The year is chosen arbitrarily. 
based on the original dataset of 2013. This explains the increase in connectedness at the beginning of 2013, since there have been no important events at this time.

Figure 13: Robustness with respect to missing observations and increased volatility

The figure illustrates two robustness checks linked to the specifics of the data set. In the left-hand panel we have tested the influence of missing observations on total connectedness. As an illustration, the total connectedness of the original data for a chosen time period in 2010 is compared to the same data, but thinned out similar to the data availability in early 2009 and late 2014 . We find the same behaviour of total connectedness. In the right-hand panel we have tested the influence of the increased volatility of the CDS data in 2013. The variance adjusted volatility leads to a higher total connectedness. This clearly suggests that the increase in total connectedness at the beginning of 2013 is not due to fundamentals, but due to changes in CMAs data cleaning and aggregation.
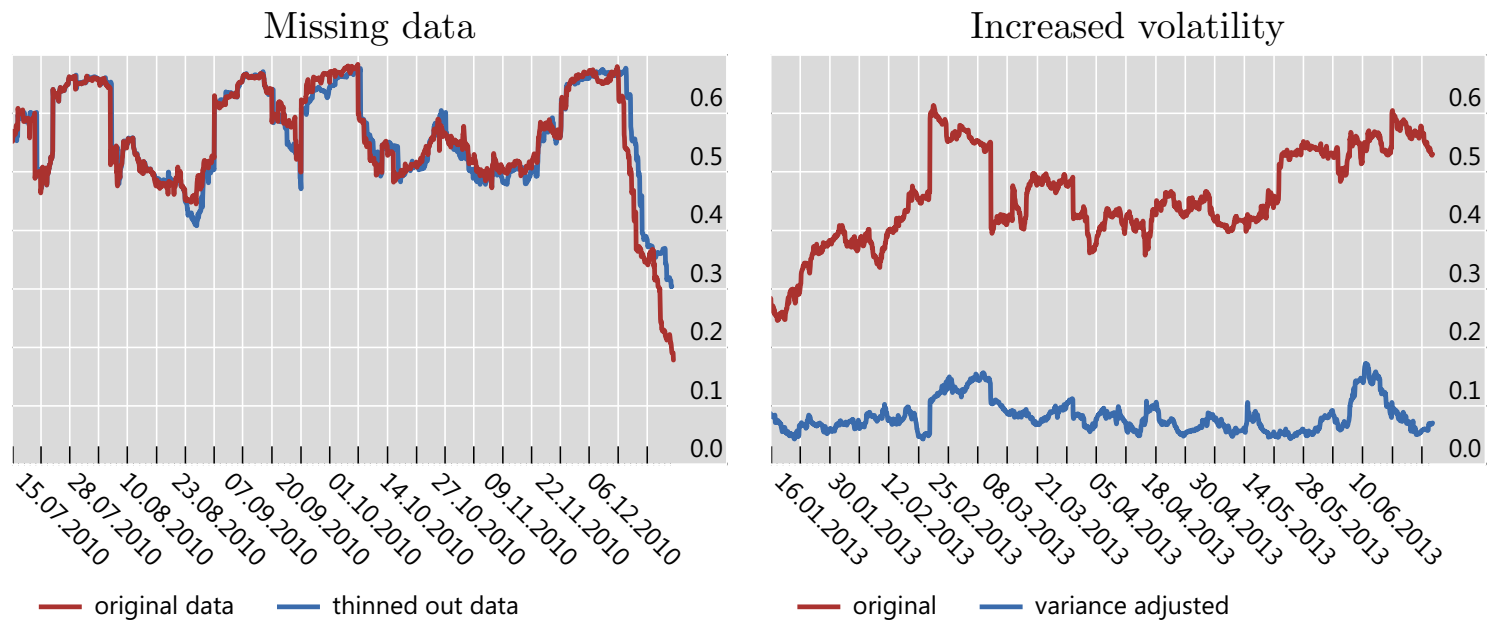

Thus, the change of data collection and aggregation by the data provider does not affect our results in Section 4 .

\section{A.3 Robustness with Respect to the choice of countries}

We evaluate the robustness of the connectedness measure with respect to the countries selected. For this purpose we compute the time evolution of overall connectedness similar to Figure 3, but now include four additional euro area members: Austria, Belgium, Finland and The Netherlands. The results presented in Figure 14 (left-hand panel) show an almost identical behavior as in Figure 3. 
Figure 14: Total connectedness for the extended set of countries

The figure illustrates the overall connectedness with $90 \%$ confidence intervals based on CDS data for 11 countries: Austria, Belgium, Finland, France, Germany, Greece, Ireland, Italy, Portugal, Spain and the Netherlands. For details on the labeling of the events, we refer to Figure 2 .

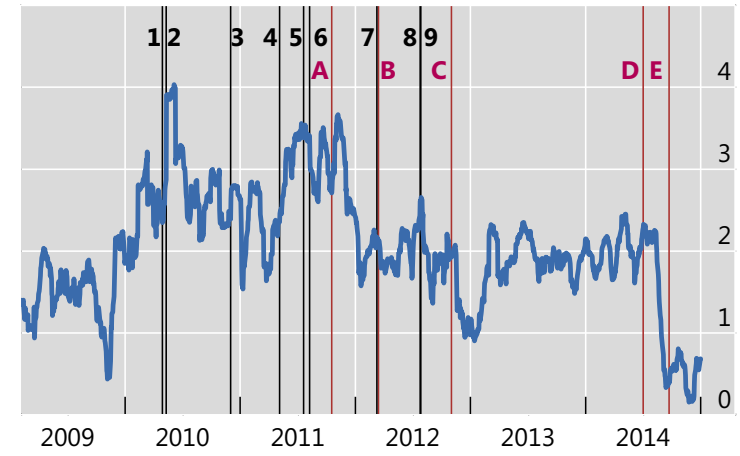

\section{A.4 Liquidity Proxys}

We present three measures of liquidity. In Figure 15 we graph relative BAS spreads defined as (ask price-bid price)/((ask price+bid price)/2). In Figure 16 we present volume data (left-hand side) and number of trade counts (right-hand side).

\section{A.5 Generalized Variance Decomposition}

Here we develop the main steps for the variance decomposition components from Equation (7) via the impulse response function. ${ }^{27}$ Koop et al. (1996) define the generalized impulse response function GI of $\mathbf{y}_{\mathbf{t}}$ at horizon $H$ for a shock of size $\delta$ and a known history $\Omega_{t-1}$ as follows:

$$
\mathbf{G I}\left(H, \delta, \boldsymbol{\Omega}_{t-1}\right)=E\left(\mathbf{y}_{t+H} / \mathbf{u}_{\mathbf{t}}=\delta, \boldsymbol{\Omega}_{t-1}\right)-E\left(\mathbf{y}_{t+H} / \mathbf{\Omega}_{t-1}\right) .
$$

For a shock only on the $j$-th element of $\mathbf{u}_{\mathbf{t}}$, the function is written as:

$$
\mathbf{G I}_{j}\left(H, \delta_{j}, \boldsymbol{\Omega}_{t-1}\right)=E\left(\mathbf{y}_{t+H} / \mathbf{u}_{\mathbf{t j}}=\delta_{j}, \boldsymbol{\Omega}_{t-1}\right)-E\left(\mathbf{y}_{t+H} / \boldsymbol{\Omega}_{t-1}\right) .
$$

In this case, the effects of the other shocks must be integrated out. For $\mathbf{u}_{t}$ normally distributed we have:

$$
E\left(\mathbf{u}_{t} / \mathbf{u}_{t j}=\delta_{j}\right)=\left(\sigma_{1 j}, \sigma_{2 j}, \cdots, \sigma_{n j}\right)^{\prime} \frac{\delta_{j}}{\sigma_{j j}}=\Sigma_{u} e_{j} \frac{\delta_{j}}{\sigma_{j j}} .
$$

Thus, the generalized impulse response is given by

${ }^{27}$ See Hamilton (1994) for the link between impulse responses and forecast error variance decomposition. 
Figure 15: Relative bid-ask spreads

The figure illustrates relative bid-ask spreads, defined as (ask price-bid price) $/(($ ask price + bid price $) / 2$ ) for the period 2008 until end 2014.
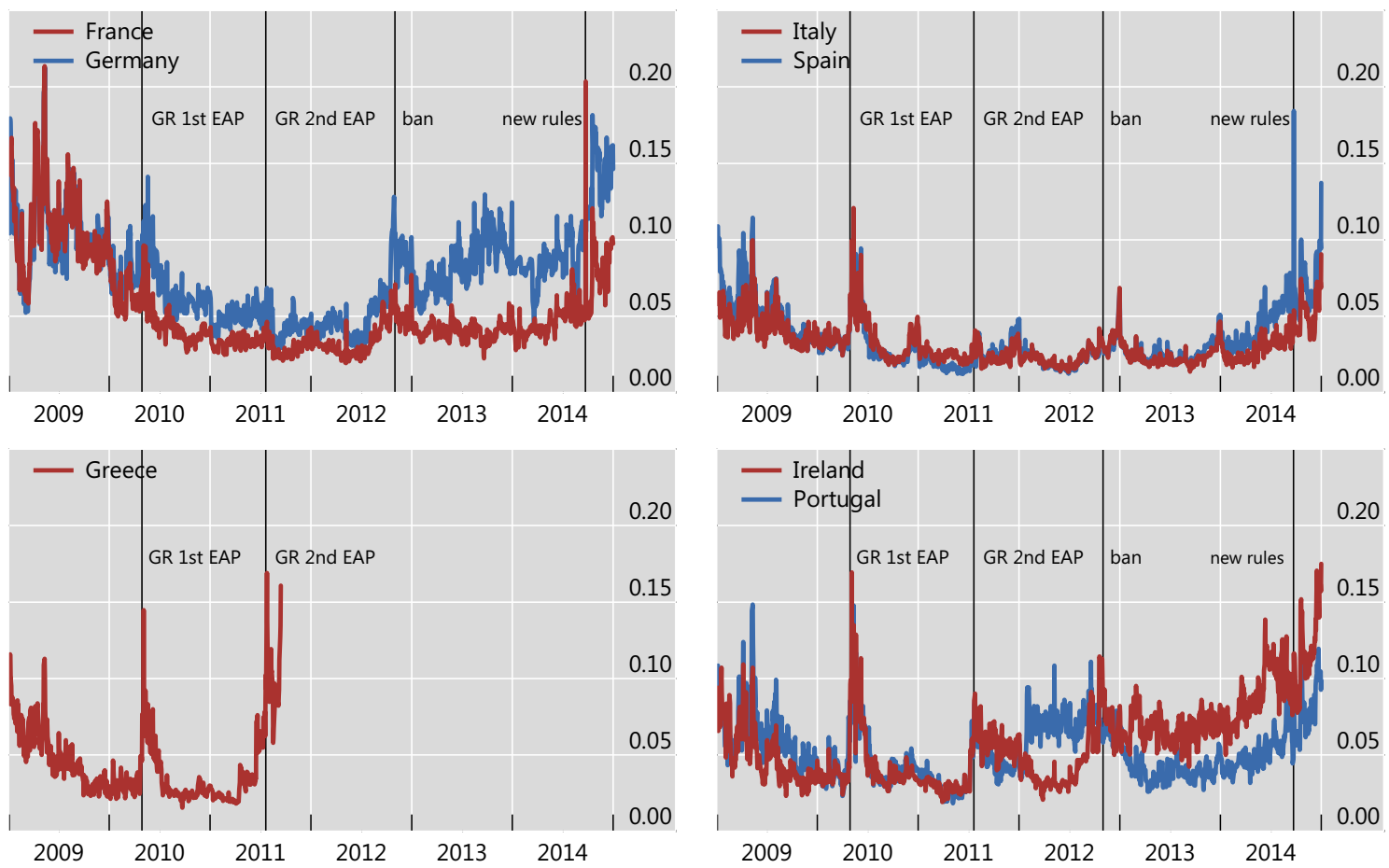

Figure 16: CDS trading volume and trade count

The figure illustrates net notional amounts outstanding (left-hand panel) and trade counts (right-hand panel), based on publicly available weekly data.

Net Notional Outstanding in USD billion

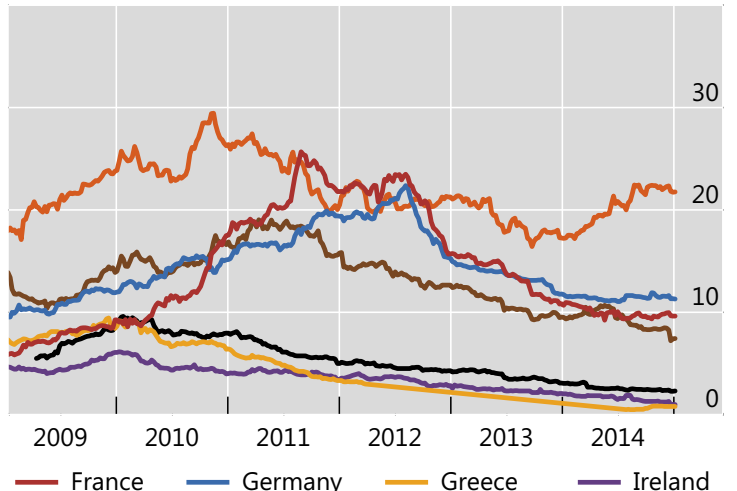

Trade count in thousands

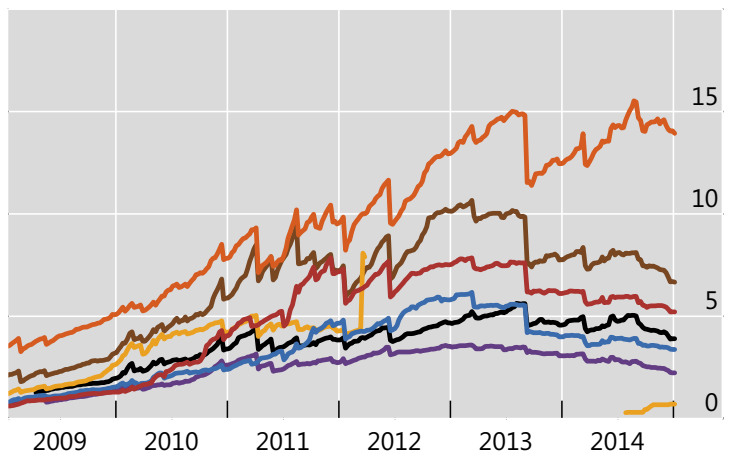

— Italy — Portugal _ Spain 


$$
\mathbf{G I}_{j}\left(H, \delta_{j}, \Omega_{t-1}\right)=\mathbf{\Phi}_{H} \Sigma_{u} e_{j} \frac{\delta_{j}}{\sigma_{j j}} .
$$

By setting $\delta_{j}=\sqrt{\sigma_{j j}}$ one obtains an impulse response function which measures the effect of one standard error shock to the $j$ th variable at time $t$ on the expected values of $\mathbf{y}$ at time $t+H$ :

$$
\mathbf{G I}_{j}\left(H, \delta_{j}, \boldsymbol{\Omega}_{t-1}\right)=\sigma_{j j}^{-1 / 2} \boldsymbol{\Phi}_{H} \Sigma_{u} e_{j} .
$$

As in Pesaran and Shin (1998), this is used to derive the generalized forecast error variance decomposition components $s_{i j}(H)$ :

$$
s_{i j}(H)=\frac{\sigma_{j j}^{-1} \sum_{h=0}^{H-1}\left(e_{i}^{\prime} \Phi_{h} \Sigma_{u} e_{j}\right)^{2}}{\sum_{h=0}^{H-1}\left(e_{i}^{\prime} \Phi_{h} \Sigma_{u} \Phi_{h}^{\prime} e_{i}\right)}
$$

\section{A.6 Overview of Crisis Related and Regulatory Events}

The sequence of regulations and crisis related events is presented Figure 2 including the total connectedness and the $90 \%$ confidence interval. The crisis related events are in black and regulatory events in purple. The choice of what date to chose in an event study is not straightforward. Usually there is close schedule of meetings and announcements in the run-up to an event, whereby different amounts of information are released or even leaked. For example, the new ISDA rules have been discussed long before mid-2014. The ISDA published proposed amendments to the 2003 Credit Derivatives Definitions already on Tuesday 15.07.2013. Nevertheless we have chosen 01.07.2014 (communication of the details of the rules) and 22.09.2014 (implementation of the rules) as the key dates.

In our analysis we have experimented with different timing of the exact dates (see Table 4). The dates used in our calculations are boldfaced. 
Table 4: Crisis Related Events

The table reports dates connected to events which are analyzed in the main body of the paper in form of event studies. We have boldfaced dates in the table which we consider as key dates for our event studies.

\begin{tabular}{|c|c|c|c|c|}
\hline \multicolumn{3}{|c|}{ Issue } & Date & vent \\
\hline 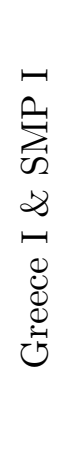 & & $\begin{array}{l}\overparen{N} \\
\infty \\
\beth\end{array}$ & $\begin{array}{l}\text { 02.05.10 Sun } \\
\text { 03.05.10 Mon } \\
\text { 05.05.10 Wed } \\
\text { 10.05.10 Mon }\end{array}$ & $\begin{array}{l}\text { official request for financial support from Greek government } \\
\text { S\&P downgrades Greece } \\
\text { EU and IMF officials hold crunch talks with German leaders. Rumours } \\
\text { of a } € 120 \text { bn package emerge } \\
\text { Eurogroup agreed to provide bilateral loans } \\
\text { MoU was signed and ECB announces that Greek bonds will be accepted } \\
\text { as collateral no matter their rating } \\
\text { S\&P downgrades Greece } \\
\text { SMP starts }\end{array}$ \\
\hline 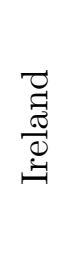 & & $\overparen{3}$ & $\begin{array}{l}\text { 21.11.10 Sun } \\
\text { 26.11.10 Fri } \\
\text { 28.11.10 Sun } \\
\text { 30.11.10 Tue } \\
\text { 01.12.10 Wed }\end{array}$ & $\begin{array}{l}\text { official request for financial support from Irish government } \\
\text { Eurogroup approves loan to Ireland } \\
\text { Troika and Ireland agreed program } \\
\text { detailed discussions ended, program finalized } \\
\text { IMF approves loan to Ireland, MoU signed }\end{array}$ \\
\hline 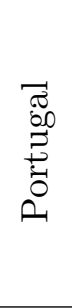 & & $\overparen{\exists}$ & $\begin{array}{l}\text { 07.04.11 Thu } \\
\text { 08.04.11 Fri } \\
\text { 03.05.11 Tue } \\
\text { 05.05.11 Thu } \\
\text { 16.05.11 Mon } \\
\text { 20.05.11 Fri }\end{array}$ & $\begin{array}{l}\text { official request for financial support from Portuguese government } \\
\text { Eurogroup approves loan } \\
\text { reaches deal for bailout } \\
\text { program was announced by Portuguese authorities } \\
\text { EU and Portuguese parliament approves bailout package } \\
\text { IMF approves loan }\end{array}$ \\
\hline 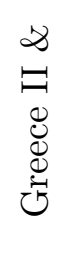 & $\underset{\sum_{1}}{\models}$ & $\begin{array}{l}6 \\
\infty \\
10\end{array}$ & $\begin{array}{l}\text { 20.07.11 Wed } \\
\text { 21.07.11 Thu } \\
\text { 08.08.11 Mon }\end{array}$ & $\begin{array}{l}\text { Merkel/Sarkozy - agreement on second bailout, private sector invol- } \\
\text { vement } \\
\text { Merkel/Sarkozy - meeting to develop common stance on } 2 \text { nd bailout } \\
\text { Euro Summit/EU - agreement on second bailout } \\
\text { SMP second wave starts }\end{array}$ \\
\hline 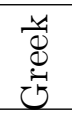 & 营 & $\mathcal{E}$ & $\begin{array}{l}01.03 .12 \text { Thu } \\
\text { 09.03.12 Fri }\end{array}$ & $\begin{array}{l}\text { ISDA declares no credit event for Greece } \\
\text { ISDA declares credit event for Greece }\end{array}$ \\
\hline 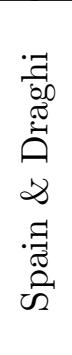 & 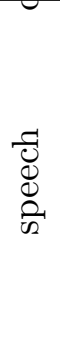 & 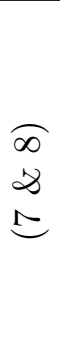 & $\begin{array}{l}\text { 09.06.12 Sun } \\
\text { 21.06.12 Thu } \\
\text { 25.06.12 Mon } \\
\text { 20.07.12 Fri } \\
\text { 23.07.12 Mon } \\
\text { 26.07.12 Thu } \\
\text { 06.09.12 Thu }\end{array}$ & $\begin{array}{l}\text { emergency meeting Euro Group regarding Spanish banks } \\
\text { decision that } 62 \text { bn euros will be shared among Spanish banks in need } \\
\text { request for assistance by Spanish government } \\
\text { Euro Group agrees bailout } \\
\text { MoU for Spanish bank bailout signed } \\
\text { Draghi speech "... whatever it takes ..." } \\
\text { OMT }\end{array}$ \\
\hline
\end{tabular}




\section{Working Paper Series in Economics}

recent issues

No. 125 Rebekka Buse, Melanie Schienle and Jörg Urban: Effectiveness of policy and regulation in European sovereign credit risk markets - A network analysis, January 2019

No. 124 Chong Liang and Melanie Schienle: Determination of vector error correction models in high dimensions, January 2019

No. 123 Rebekka Buse and Melanie Schienle: Measuring connectedness of euro area sovereign risk, January 2019

No. 122 Carsten Bormann and Melanie Schienle: Detecting structural differences in tail dependence of financial time series, January 2019

No. 121 Christian Conrad and Melanie Schienle: Testing for an omitted multiplicative long-term component in GARCH models, January 2019

No. 120 Marta Serra-Garcia and Nora Szech: The (in)elasticity of moral ignorance, December 2018

No. 119 Thomas Mariotti, Nikolaus Schweizer, Nora Szech and Jonas von Wangenheim: Information nudges and self-control, November 2018

No. 118 Andranik S. Tangian: Methodological notes on composite indicators for monitoring working conditions, October 2018

No. 117 Andranik S. Tangian: Testing the improved third vote during the 2018 election of the Karlsruhe Institute of Technology student parliament, September 2018

No. 116 Yuri Golubev and Mher Safarian: On robust stopping times for detecting changes in distribution, May 2018

No. 115 Daniel Hoang, Sebastian Gatzer and Martin Ruckes: The economics of capital allocation in firms: Evidence from internal capital markets, January 2018 